\title{
Effect of Disturbance Regimes on Spatial Patterns of Tree Species in Three Sites in a Tropical Evergreen Forest in Vietnam
}

\author{
Do Thi Ngoc Le, ${ }^{1,2}$ Nguyen Van Thinh,, ${ }^{1,3}$ Nguyen The Dung, ${ }^{2}$ and Ralph Mitlöhner ${ }^{1}$ \\ ${ }^{1}$ Tropical Silviculture \& Forest Ecology, Georg-August-Universität Göttingen, Büsgenweg 1, 37077 Göttingen, Germany \\ ${ }^{2}$ Vietnam Forestry University, Xuan Mai Town, Chuong My District, Hanoi 100000, Vietnam \\ ${ }^{3}$ Silvicultural Research Institute (SRI), Vietnamese Academy of Forest Sciences, Duc Thang, Bac Tu Liem District, \\ Hanoi 100000, Vietnam
}

Correspondence should be addressed to Do Thi Ngoc Le; dothingocle81@yahoo.com

Received 7 August 2015; Revised 3 November 2015; Accepted 17 December 2015

Academic Editor: Scott D. Roberts

Copyright (C) 2016 Do Thi Ngoc Le et al. This is an open access article distributed under the Creative Commons Attribution License, which permits unrestricted use, distribution, and reproduction in any medium, provided the original work is properly cited.

\begin{abstract}
The effects of disturbance regimes on the spatial patterns of the five most abundant species were investigated in three sites in a tropical forest at Xuan Nha Nature Reserve, Vietnam. Three permanent one-ha plots were established in undisturbed forest (UDF), lightly disturbed forest (LDF), and highly disturbed forest (HDF). All trees $\geq 5 \mathrm{~cm} \mathrm{DBH}$ were measured in twenty-five $20 \mathrm{~m} \times 20 \mathrm{~m}$ subplots. A total of 57 tree species belonging to 26 families were identified in the three forest types. The UDF had the highest basal area $\left(30 \mathrm{~m}^{2} \mathrm{ha}^{-1}\right)$, followed by the $\operatorname{LDF}\left(17 \mathrm{~m}^{2} \mathrm{ha}^{-1}\right)$ and the $\operatorname{HDF}\left(13.0 \mathrm{~m}^{2} \mathrm{ha}^{-1}\right)$. The UDF also had the highest tree density (751 individuals $\mathrm{ha}^{-1}$ ) while the HDF held the lowest (478 individuals ha ${ }^{-1}$ ). Across all species, there were 417 "juveniles," 267 "subadults," and 67 "adults" in the UDF, while 274 "juveniles," 230 "subadults," and 36 "adults" were recorded in the LDF. 238 "juveniles," 227 "subadults," and 13 "adults" were obtained in the HDF. The univariate and bivariate data with pair- and markcorrelation functions of intra- and interspecific interactions of the five most abundant species changed in the three forest types. Most species indicated clumping or regular distributions at small scale, but a high ratio of negative interspecific small-scale associations was recorded in both the LDF and HDF sites. These were, however, rare in the UDF.
\end{abstract}

\section{Introduction}

A forest stand comprises a set of trees characterized by their locations and sizes. Tree diameter distributions can provide information on tree sizes but cannot address tree locations. However, tree diameters are associated with tree positions, and growth is sensitive to both spatial interaction among trees [1] and local habitat characteristics [2]. The theory of marked point processes provides a formal framework for an analysis of the spatial characteristics of tree diameter distributions, in which the points indicate tree locations and the marks denote particular tree characteristics such as diameter at breast height, tree height, and growth during a given time span $[3,4]$. Ecologists have become increasingly interested in studying spatial patterns in ecology [5-8]. In addition, tree species associations at different life stages or age classes have already received considerable attention [5, 9-11]. The spatial pattern of a particular species, especially the adult-juvenile relationship, provides useful information on the species' regeneration process $[10,12,13]$. The spatial pattern of trees is an important indicator of stand history, population dynamics, and species interaction in forests [14, 15], all of which are helpful in understanding mechanistically the processes and patterns of plant communities [16].

Spatial distributions and the spatial patterns (both vertical and horizontal) of trees in forests are important elements for understanding forest ecosystem dynamics [17]; however, the potential for ecological understanding has not yet been fully recognized [18]. A spatial point pattern is a set of locations, distributed within a region of interest, which have been generated by some spatial process [19]. Many methods and indices have been developed in order to interpret and assess spatial distributions [20-23]. The spatial distribution pattern, within plant populations, is influenced by various ecological and evolutionary processes which take place during the life history of a plant, such as seed dispersal, intra- and 
interspecific competition, and environmental heterogeneity. The spatial structure of a forest is largely determined by the relationships within neighboring groups of trees [24]. The main factors in a forest structure are the spatial distribution, species diversity, and variations in tree dimensions [25]. In recent decades, several structural indices such as the Clark and Evans aggregation index [20], pair-correlation function [26], and species diversity indices [13] have been developed to quantify spatial forest structure.

Tropical rain forests have been used in recent studies to demonstrate the effects of high diversity on spatial distribution $[5,27]$. This explains why interspecific species have functional similarity and may adapt to average environment conditions [28]. One approach to exploring spatial plant dynamics is to use a point pattern analysis of fully mapped plant locations [29]. Spatial statistics like Ripley's $K$ function [23] and the pair-correlation function $[26,30]$ quantify the smallscale spatial correlation structure of a pattern which contains information on positive/negative interactions among plants. In addition, point pattern analysis is ideally suited to control for environmental heterogeneity and focus on neighborhood processes. Spatial patterns of individuals within populations are closely linked to ecological processes; consequently, ecological processes may be deduced from spatial patterns [3133].

There is little published information on the spatial patterns of tree species in tropical evergreen forests as affected by different disturbance regimes in Vietnam. In the present study, univariate $g(r)$ statistics with the null model of complete spatial randomness and the mark-correlation function were used for point pattern analysis at different scales. We analyzed the intraspecific and interspecific association (relationship or correlation) of five abundant tree species in three forest types in a tropical evergreen forest in Xuan Nha Nature Reserve, Vietnam. This study will provide meaningful knowledge for predicting the spatial patterns of the most dominant tree species after disturbance and could have further silvicultural implications for management practice (e.g., selecting native tree species and choosing site conditions for enrichment planting) in restoration zones of the nature reserve.

\section{Materials and Methods}

2.1. Study Site. The study site (Figure 1) is located in Xuan Nha Nature Reserve $\left(20^{\circ} 36^{\prime}-20^{\circ} 48^{\prime} \mathrm{N}, 104^{\circ} 29^{\prime}-104^{\circ} 50^{\prime} \mathrm{E}\right)$. The reserve has a total area of 27,100 ha, of which 15,300 are tropical evergreen forests and 2,600 are tropical forests on limestone [34]. The nature reserve's elevation ranges from 300 to $2,000 \mathrm{~m}$ above sea level. The topography is composed of two shallow-sided valleys, which run across the reserve from the Laotian border. Xuan Nha Nature Reserve is located in a tropical monsoon climate where the mean temperature is $21.3^{\circ} \mathrm{C}$. The rainy season lasts from May to October (with a maximum of $332.4 \mathrm{~mm}$ of rain in August), while the dry season goes from November to April (with a minimum of $32.4 \mathrm{~mm}$ in February). Mean annual precipitation is about $1,673 \mathrm{~mm}$. Six major soils are found in the study site: (1) thick layers of dark yellow ferralsols at 700-1,700 $\mathrm{m}$ in altitude that develop on shale or metamorphic rocks with a medium

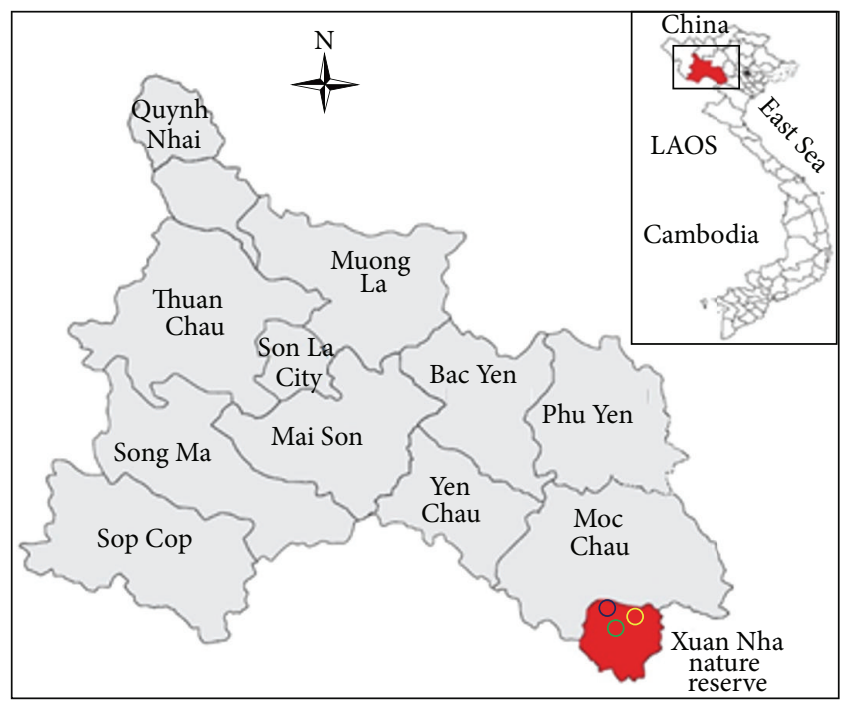

Figure 1: The location of Xuan Nha Nature Reserve in Vietnam. Dark blue, yellow, and green colors indicate the undisturbed forest (UDF), lightly disturbed forest (LDF), and highly disturbed forest (HDF), respectively.

texture; (2) thin layers of yellow-brown ferralsols at 7001,700 m altitude which develop on limestone or metamorphic limestone and have coarse to medium texture; (3) thick layers of light yellow ferralsols at 700-1,700 $\mathrm{m}$ on shale or metamorphic rocks with medium texture; (4) thick layers of light/greyyellow ferralsols that develop at 300 to $1,000 \mathrm{~m}$ in low hilly or mountainous regions on slate, siltstone, sandstone, and conglomerate with a coarse to medium texture; (5) grey-yellow ferralsols modified by paddy fields with medium texture that appear in the surrounding villages; and (6) alluvial soils deposited at the foot of mountains, river banks, and streams [35].

In accordance with the collected data, approximately $43 \%$ of the forest area (app. 7,872.20 hectares) is disturbed, while $42.8 \%(7,821.4 \mathrm{ha})$ is classified as undisturbed (Table 1$)$. This disturbed area is divided into two categories: lightly disturbed and heavily disturbed. Undisturbed and disturbed forests refer to different disturbance regimes, where "disturbance" is defined as the impact level of human activities in the forest. Disturbance in this context refers to selective timber harvesting, felling small-sized trees for nontimber products, and past (pre-2003) illegal logging.

Undisturbed forests (primary or rich forests) are areas that do not show evidence of damage from human activities; these are relatively stable forests not yet (or less) influenced by humans or natural disasters. Because such forests are limited to inaccessible and protected areas, they are not used for production purposes. UDFs are extremely rich forests with a timber volume of standing trees between 201 and $300 \mathrm{~m}^{3} \mathrm{ha}^{-1}$. LDFs (average forest) are influenced by humans or natural disasters, leading to changes in their structure. This type demonstrates low and minor damage from human beings and has a timber reserve of standing trees between 101 and $200 \mathrm{~m}^{3} \mathrm{ha}^{-1}$. Forests may be classified as LDFs if past logging 
TABLE 1: Stratification of vegetation types and characteristics of three main forest types at Xuan Nha Nature Reserve, Vietnam.

\begin{tabular}{|c|c|c|c|c|c|}
\hline Forest type & Area (ha) & Species richness $(N /$ ha $)$ & Family richness $(N /$ ha $)$ & Tree density $(\mathrm{N} / \mathrm{ha})$ & Basal area $\left(\mathrm{m}^{2} / \mathrm{ha}\right)$ \\
\hline Undisturbed (rich forest) & $7,821.4$ & 49 & 25 & 751 & 29.8 \\
\hline Lightly disturbed (average forest) & $2,288.5$ & 42 & 21 & 540 & 16.9 \\
\hline Heavily disturbed (poor forest) & $2,179.5$ & 30 & 18 & 478 & 13.0 \\
\hline Wood and bamboo mixed forest & 483.2 & - & - & - & - \\
\hline Bamboo forest & $2,921.0$ & - & - & - & - \\
\hline Limestone forest & $1,549.4$ & - & - & - & - \\
\hline Nonforested lands & $1,024.5$ & - & - & - & - \\
\hline Total & $18.267,5$ & & & & \\
\hline
\end{tabular}

has resulted in the removal of only 6 to $10 \%$ of trees above a minimum harvestable size $(40-50 \mathrm{~cm}$ DBH). HDFs (postexploitation forests, poor forests) are degraded as a result of human activities that have severely impacted their canopy structure, productivity, and volume at various levels. Such forests have been exploited for their timber or other forest products. 10 to $30 \%$ of trees above a minimum harvestable size $(40-50 \mathrm{~cm} \mathrm{DBH})$ have been removed, and they have a reserve of standing trees between 10 and $100 \mathrm{~m}^{3} \mathrm{ha}^{-1}$.

The reserve has a high tree species diversity with 173 families and 1,074 species. The main vegetation observed at Xuan Nha Nature Reserve is monsoon evergreen broadleaved forest; numerous rare species of flora have been found here, including 65 rare tree species that account for $6.1 \%$ of the total species listed in Vietnam's Red Book [35]. At the UDF, Lithocarpus ducampii is the most dominant species, followed by Syzygium cuminii, Vatica odorata, Toxicodendron succedaneum, and Cinnamomum parthenoxylon. Lithocarpus ducampii, Vatica odorata, and Syzygium cuminii dominated in the LDF, while Engelhardtia roxburghiana and Nephelium melliferum could be found in the HDF. In the UDF, the five most dominant and species-rich families were Lauraceae, Fagaceae, Myrtaceae, Dipterocarpaceae, and Anacardiaceae. Fagaceae was the most important family in the LDF, followed by Lauraceae, Sapindaceae, Dipterocarpaceae, and Myrtaceae. Anacardiaceae dominated only in the UDF; Juglandaceae was restricted to the HDF. The top family in the HDF was Lauraceae, followed by Dipterocarpaceae, Sapindaceae, Juglandaceae, and Fagaceae. Across the three forest types, Lauraceae was the most dominant, but Fagaceae, Myrtaceae, and Dipterocarpaceae were also common families. The tree density of the LDF was lower than that of the UDF, which had the highest density ( 751 trees $^{-1}$ ) of all trees $\geq 5 \mathrm{~cm} \mathrm{DBH}$ among the three forest sites; the HDF held the lowest tree density (478 stems ha ${ }^{-1}$ ).

2.2. Sampling Design. Three permanent one-ha plots $(100 \mathrm{~m}$ $\times 100 \mathrm{~m}$ each) were established in undisturbed, lightly disturbed, and highly disturbed forests (one plot each) in 2003. The corners of each plot were marked with a concrete post and a GPS device. Each one-ha plot was further divided into twenty-five $400 \mathrm{~m}^{2}$ subplots $(20 \mathrm{~m} \times 20 \mathrm{~m})$ (Figure 2).

2.3. Data Collection. Data were collected in 2013. Within each plot, all living trees larger than $5 \mathrm{~cm}$ in diameter at breast

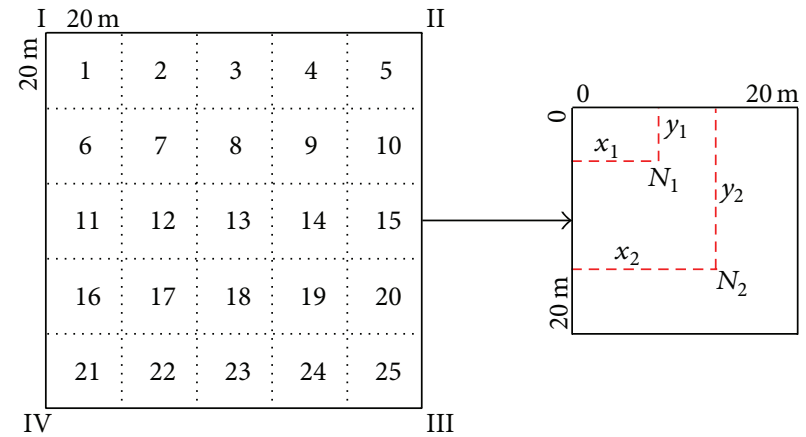

FIGURE 2: Sampling design (sample size: 1 ha). Symbols I, II, III, and IV are the four corners of the sampled plot. 25 subplots $(20 \mathrm{~m} \times$ $20 \mathrm{~m}$ ) were set up in order to measure the coordinates of all trees with $\mathrm{DBH} \geq 5 \mathrm{~cm} . N_{1}\left(x_{1}, y_{1}\right) ; N_{2}\left(x_{2}, y_{2}\right)$ are the tree coordinates sampled.

height (DBH $1.3 \mathrm{~m}$ ) were marked with paint and their $\mathrm{DBH}$ and height were measured. All individuals were classified into three life history stages: "juveniles" $(5 \mathrm{~cm} \leq \mathrm{DBH}<10 \mathrm{~cm})$, "subadults" $(10 \mathrm{~cm} \leq \mathrm{DBH}<30 \mathrm{~cm})$, and "adults" $(\mathrm{DBH} \geq$ $30 \mathrm{~cm}$ ) [36]. Tapes were used to measure the coordinates of trees as follows: the starting point in each subplot $\left(400 \mathrm{~m}^{2}\right)$ was fixed at the northwestern corner. The position of each tree ( $X, Y$ coordinates) was determined by measuring the distance to the two edges of the plot (Figure 2). All trees were recorded and labelled in order to avoid missing any ones. Tree species were identified in the field with specialists' help; unidentifiable specimens were taken to the Vietnam Forestry University Herbarium for identification.

2.4. Data Analysis. Tree density ( from the count of all individuals from the 25 subplots; tree basal area (BA, $\mathrm{m}^{2} \mathrm{ha}^{-1}$ ) was calculated by using the following equation: $\mathrm{BA}=\left(3.14 \times(\mathrm{DBH})^{2}\right) / 4\left(\mathrm{~m}^{2}\right)$. The total basal area per ha was calculated by the sum of the BA of all trees in the 25 subplots. Species richness was taken by counting the number of species occurring in all subplots of each forest type [22]. The R-package software was used to measure nearest neighbor distance (NND) [37]. Only the five most abundant tree species in the three forest types were used to simulate spatial distributions and the relationships among them. Paircorrelation functions $g(r)$, mark-correlation functions, and null models were used to analyze spatial patterns in this study. 
2.4.1. Pair-Correlation Functions. The pair-correlation function was used as a summary statistic to quantify the spatial structure of the uni- and bivariate patterns $[8,26]$. Based on intertree distances, the univariate pair-correlation function $g_{11}(r)$ can be used to determine whether a point distribution is random, aggregated/clustered, or regular at distance $r$ in which those patterns occur. The parameter $g(r)$ indicates whether a pattern is random (complete spatial randomness $(\mathrm{CSR}) ; g(r)=1)$, clumped $(g(r)>1)$, or regular $(g(r)<1)$ at a given radius $r$.

The pair-correlation function $g_{11}(r)$ for the univariate pattern of species 1 can be defined based on the neighborhood density $O_{11}(r)=\lambda_{1} g_{11}(r)$, that is, the mean density of trees belonging to species 1 , surrounded by rings with radius $r$ and width $d(r)$ [8], where $\lambda_{1}$ is the intensity (number of species 1's trees in the plot). Under the null model of complete spatial randomness (CSR), the points are independently and randomly distributed over the entire plot [8]. The values of $g_{11}(r)$ within the $95 \%$ confidence envelope indicate that the spatial structure of the given distances does not differ significantly from the CSR. Values of $g_{11}(r)$ above $95 \%$ confidence envelope indicate that a distance class is more aggregated than under CSR; values of $g_{11}(r)$ below the $95 \%$ confidence envelope indicate lower aggregation (approaching a more regular pattern) at that scale [38]. The pair-correlation function for bivariate patterns (composed of trees from species 1 and 2) follows, where the quantity $g_{12}(r)$ is the ratio of the observed mean density of species 2's trees in the rings around species 1's trees to the expected mean density of species 2's trees in those rings [8]. The corresponding neighborhood density function yields $O_{12}(r)=\lambda_{2} g_{12}(r) \cdot g_{12}(r)=1$ shows independence (no interaction), $g_{12}(r)>1$ indicates attraction between two point patterns at distance $r$, and $g_{12}(r)<1$ indicates repulsion/inhibition between the two patterns at distance $r$.

2.4.2. Effect of Interspecific Competition on Tree Growth. A mark-correlation function (MCF) $K_{m m}(r)$ [26, 39] using $\mathrm{DBH}$ as marks was used to analyze the distance-dependent size correlation of trees for distances up to $50 \mathrm{~m}$. The similarity or dissimilarity between the DBH marks of two trees at a distance $r$ apart is quantified by the equation $f\left(m_{1}, m_{2}\right)=$ $m_{1} \times m_{2}$, where $m_{1}$ and $m_{2}$ are the $\mathrm{DBH}$ values of two neighboring trees. $K_{m m}(r)$ is defined as the normalized mean value of $f\left(m_{1}, m_{2}\right)$ for all marks at distance $r$. Marks are considered independent and positively or negatively correlated at distance $r$ if $K_{m m}(r)=1, K_{m m}(r)>1$, or $K_{m m}(r)<1$, respectively.

2.4.3. Null Models. The univariate statistic is used to analyze the spatial pattern of one object, while the bivariate statistic is used to analyze the spatial association of two objects (pattern 1 and pattern 2) [8, 40]. Based on a homogeneity test on the spatial pattern of all adult trees $(\mathrm{DBH} \geq 10 \mathrm{~cm})$, we applied complete spatial randomness (CSR) as the null model $[8,39]$. A Monte-Carlo approach was used to test for significant departures from the null models. Each of the 199 simulations of a point process underlying the null model generates a summary statistic; simulation envelopes with $\alpha<$ 0.05 were calculated from the fifth highest and lowest values of the 199 simulations [26]. All analyses were performed using the software Programita [8].

\section{Results}

3.1. Population Structure of Individuals in the Three Life Stages. The adults of all tree species were used to test for environmental heterogeneity in the three forest types. The five most abundant species (Engelhardtia roxburghiana, Lithocarpus ducampii, Syzygium cuminii, Nephelium melliferum, and Cinnamomum parthenoxylon; Table 2) were analyzed for all other associations (e.g., intra-and interspecific). Across all species, there was a higher proportion of "juveniles," "subadults," and "adults" in the UDF than in the LDF or HDF. All tree species across the three life stages are mapped in Figure 3.

The diameter distributions of the five most abundant species are shown in Figure 4. The frequency distribution of all tree species demonstrated an inverted J-shaped curve in which the number of individuals gradually decreased with increasing diameter classes, a trend found across all three forest sites. The distribution of Engelhardtia roxburghiana varied among the three forest types; a unimodal distribution was found in the HDF (Figure 4(c)), whereas the UDF and LDF had reverse J-shapes (Figures 4(a) and 4(b)). Conversely, Syzygium cuminii displayed a unimodal distribution in all three forest types. Both species had no individuals in the size class greater than $30 \mathrm{~cm}$, and $88.4 \%$ of the total tree density came from the $5-20 \mathrm{~cm}$ diameter class. However, a very high abundance of 5-10 cm DBH individuals of L. ducampii and a high number of $10 \mathrm{~cm} \mathrm{~S}$. cuminii trees were observed in the UDF.

3.2. Intraspecific Interactions. The spatial patterns of the five most abundant species in the three forest types are shown in Figure 5; the univariate $g(r)$ statistics with the null model of complete spatial randomness (CSR) displayed different spatial patterns for these species at various scales. There were no statistically significant departures from randomness for Engelhardtia roxburghiana in the HDF (Figure 6(a)), but, in the UDF, it was clumped at scales of $6 \mathrm{~m}$ and $9-10 \mathrm{~m}$ (Figure 5(a)). Cinnamomum parthenoxylon was aggregated at scales of 13 and $28 \mathrm{~m}$ in the UDF (Figure 5(d)) and randomly distributed at all distances in both the HDF and LDF sites (Figures 6(c) and 6(d)). Engelhardtia roxburghiana in the LDF and Cinnamomum parthenoxylon in the HDF both occurred in larger spatial clusters of trees $(>40 \mathrm{~m})$ and were thus evidence for clustering at larger spatial scales. Lithocarpus ducampii was significantly aggregated at a scale of $9 \mathrm{~m}$ in the HDF (Figure 5(b)), but predominantly random in the LDF (Figure 5(c)) and UDF (Figure 6(b)). Syzygium cuminii was significantly aggregated at a large scale of $39 \mathrm{~m}$ in the HDF (Figure 5(e)) but showed an independent distribution at all scales in the LDF (Figure 6(e)); no significant pattern was found at all scales in the UDF (Figure 6(f)). Nephelium melliferum, in contrast, was randomly distributed at all distances in the HDF (Figure 6(g)) but tended to have a regular distribution at a larger scale $(>50 \mathrm{~m})$ in the LDF (Figure $6(\mathrm{~h})$ ). This species displayed clumped distribution at two scales of 4 and $16 \mathrm{~m}$ in the UDF (Figure 5(f)). Cinnamomum parthenoxylon 
TABLE 2: The five most abundant tree species of each forest site in Xuan Nha Nature Reserve, Vietnam.

\begin{tabular}{|c|c|c|c|c|c|}
\hline Species & Tree density $[N /$ ha $]$ & Basal area $\left[\mathrm{m}^{2} / \mathrm{ha}\right]$ & Mean DBH $[\mathrm{cm}]$ & Maximum DBH $[\mathrm{cm}]$ & Median NN [m] \\
\hline \multicolumn{6}{|l|}{ Undisturbed forest } \\
\hline S. cuminii & 103 & 2.17 & 15.5 & 28.2 & 12.33 \\
\hline L. ducampii & 78 & 4.91 & 22.4 & 119.5 & 14.95 \\
\hline N. melliferum & 53 & 1.75 & 17.7 & 60.3 & 11.94 \\
\hline C. parthenoxylon & 50 & 2.73 & 23.1 & 61.8 & 13.68 \\
\hline E. roxburghiana & 46 & 2.61 & 21.2 & 70.1 & 12.98 \\
\hline \multicolumn{6}{|c|}{ Lightly disturbed forest } \\
\hline L. ducampii & 96 & 2.80 & 15.4 & 55.4 & 10.99 \\
\hline S. cuminii & 60 & 1.17 & 14.9 & 28.2 & 9.70 \\
\hline C. parthenoxylon & 50 & 1.46 & 17.8 & 41.4 & 11.58 \\
\hline E. roxburghiana & 44 & 1.28 & 16.9 & 42.7 & 13.29 \\
\hline N. melliferum & 42 & 1.27 & 17.5 & 41.7 & 12.00 \\
\hline \multicolumn{6}{|c|}{ Heavily disturbed forest } \\
\hline E. roxburghiana & 61 & 1.80 & 17.3 & 57.0 & 5.66 \\
\hline L. ducampii & 50 & 1.60 & 17.6 & 42.0 & 12.70 \\
\hline S. cuminii & 49 & 0.89 & 14.2 & 42.0 & 11.34 \\
\hline N. melliferum & 47 & 1.26 & 17.0 & 28.0 & 11.76 \\
\hline C. parthenoxylon & 42 & 1.32 & 18.9 & 32.0 & 12.45 \\
\hline
\end{tabular}

and Nephelium melliferum in both the HDF and LDF sites showed a random spatial distribution at all distances up to $50 \mathrm{~m}$.

The mark-correlation function showed different spatial distributions of the five most abundant tree species. For Engelhardtia roxburghiana, only a negative correlation was detected at scales of up to $2 \mathrm{~m}$ in the HDF (data not shown), but there was a significant positive association in the range of 14-15 $\mathrm{m}$ in the LDF (Figure 7(a)); no statistically significant correlation was found in the UDF. Lithocarpus ducampii had a positive correlation at scales of $26 \mathrm{~m}$ in the HDF (Figure 7(b)) and 1 and $5-6 \mathrm{~m}$ in the LDF (Figure 7(c)); in the UDF, it exhibited a negative association at 16-17 and 48-49 m (Figure $7(\mathrm{~d})$ ). Cinnamomum parthenoxylon displayed a similar negative correlation at different scales of 22-23 $\mathrm{m}$ in the HDF (Figure 7(e)), 3-6 $\mathrm{m}$ in the LDF (Figure 7(f)), and $8 \mathrm{~m}$ in the UDF (Figure $7(\mathrm{~g})$ ). Only two instances of relationship were observed for Syzygium cuminii: one was positive at 7 and $9 \mathrm{~m}$; the other was negative at a distance of $12 \mathrm{~m}$ in the HDF (Figure $7(\mathrm{~h})$ ). Nephelium melliferum demonstrated positive trends at a scale of $4 \mathrm{~m}$ and a negative correlation at distance of $8 \mathrm{~m}$ in the HDF (Figure 7(i)). In the LDF, it tended to have a negative correlation at the particular scales of 24 and $47 \mathrm{~m}$ (Figure $7(\mathrm{j})$ ) and a positive association in the UDF at the scales of 28-29 m (Figure 7(k)).

3.3. Interspecific Interactions. The results of the bivariate spatial pattern analysis using pair- and mark-correlation functions for the five abundant species in the three forest types are shown in Figure 8 . A total of $20(5 \times 4)$ bivariate point pattern analyses were simulated for pairs of the five most abundant tree species. Engelhardtia roxburghiana and Lithocarpus ducampii showed a trend for positive association (statistical attraction) at scales of 17 and $42 \mathrm{~m}$ in the HDF
(Figure 8(a)); in the UDF, they demonstrated a positive correlation at scales of 6 and $15 \mathrm{~m}$ and a negative association at a distance of 2-3 m (Figure 8(b)). However, this relationship was independently distributed at all scales in the LDF. There was a significant positive association (attraction) between Engelhardtia roxburghiana and Cinnamomum parthenoxylon at distances of 6 and $28 \mathrm{~m}$ in the LDF (Figure 8(c)) and $39 \mathrm{~m}$ (Figure $8(\mathrm{~d})$ ) in the HDF, but no such association was found at all scales in the UDF. Engelhardtia roxburghiana showed no interaction with Syzygium cuminii at all distances for both the LDF and HDF; however, a significant positive association was detected between the two at the specific scales of $4,7,10,16$, and $21 \mathrm{~m}$ in the UDF (Figure 8(e)). Between Engelhardtia roxburghiana and Nephelium melliferum, there was only a negatively associated trend at scales of 33 and $8 \mathrm{~m}$ in the HDF and UDF (Figures 8(f) and $8(\mathrm{~g})$ ). Two instances of statistically significant departures from randomness were obtained between Lithocarpus ducampii and Cinnamomum parthenoxylon in the HDF: one was towards repulsion distribution at a small distance of $5 \mathrm{~m}$; the other towards positive association at a scale of $22 \mathrm{~m}$ (Figure 8(h)). In the LDF, no spatial interaction of Lithocarpus ducampii and Cinnamomum parthenoxylon was recorded at all distances. Lithocarpus ducampii and Syzygium cuminii were significantly segregated (attraction) at a small distance of $7 \mathrm{~m}$ and negatively associated (repulsion) at $11 \mathrm{~m}$ in the HDF (Figure 8(i)); in comparison, this relationship in the LDF showed significant repulsion at the scales of 4 and $33 \mathrm{~m}$ (Figure $8(\mathrm{j})$ ). The only clear significant aggregation obtained was for the interaction between Lithocarpus ducampii and Syzygium cuminii at the small scales of 4 and $7 \mathrm{~m}$ as well as the larger distances of 16 and $28 \mathrm{~m}$ in the UDF (Figure $8(\mathrm{k})$ ). A similar result was recorded for Lithocarpus ducampii and Nephelium melliferum at different distances; in the HDF, the relationship exhibited a 


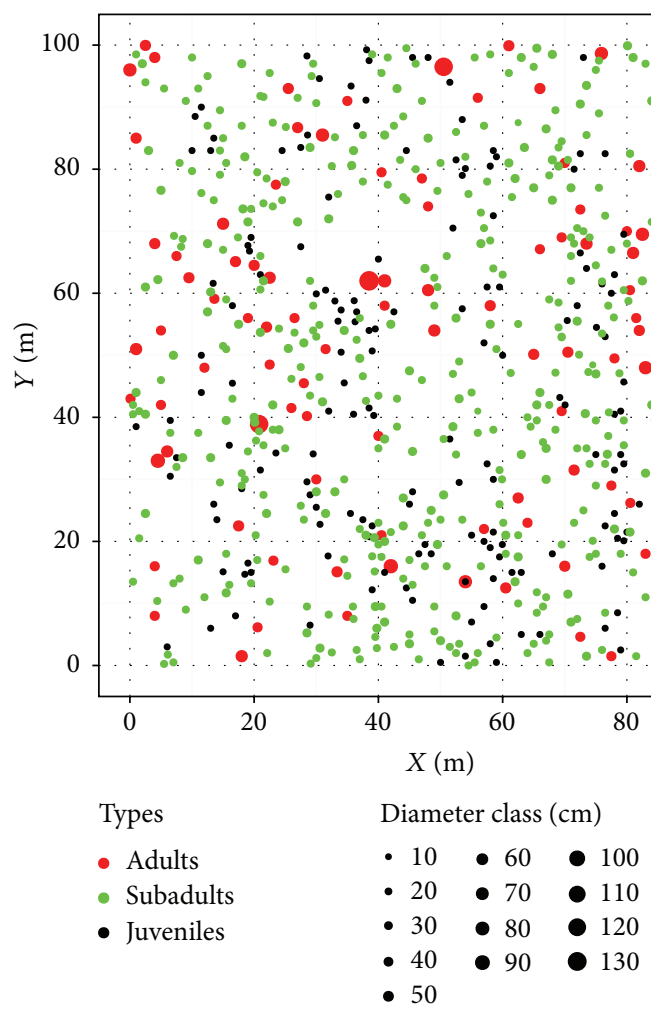

(a)

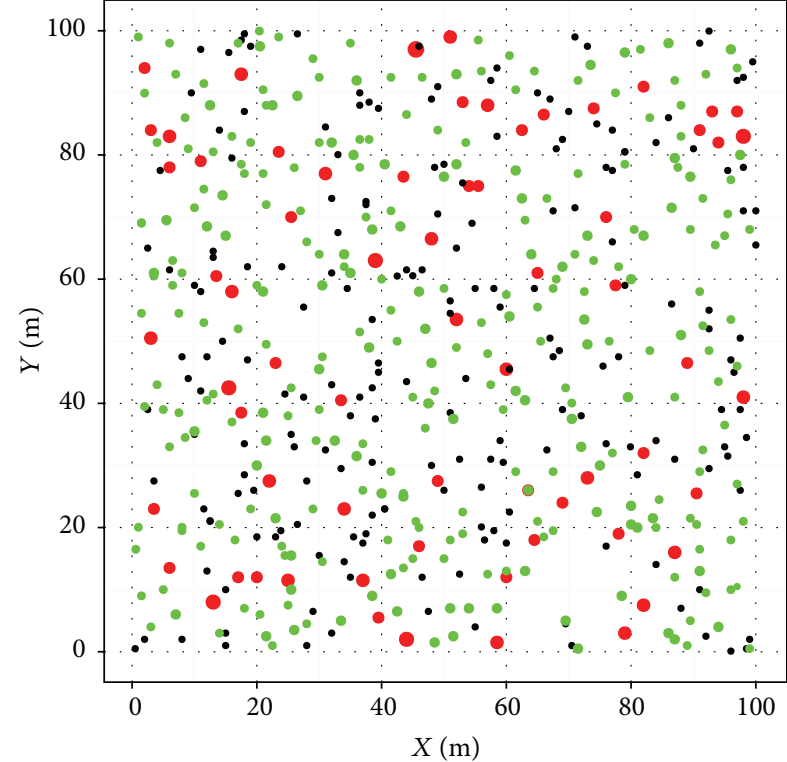

Types

Diameter class $(\mathrm{cm})$

$\begin{array}{llll}\text { - Adults } & \bullet 10 & \bullet 60 & \bullet 100 \\ \text { - Subadults } & \bullet 20 & \bullet 70 & \bullet 110 \\ \text { - Juveniles } & \bullet 30 & \bullet 80 & \bullet 120 \\ & \bullet 40 & \bullet 90 & \bullet 130 \\ & \bullet 50 & & \end{array}$

(b)

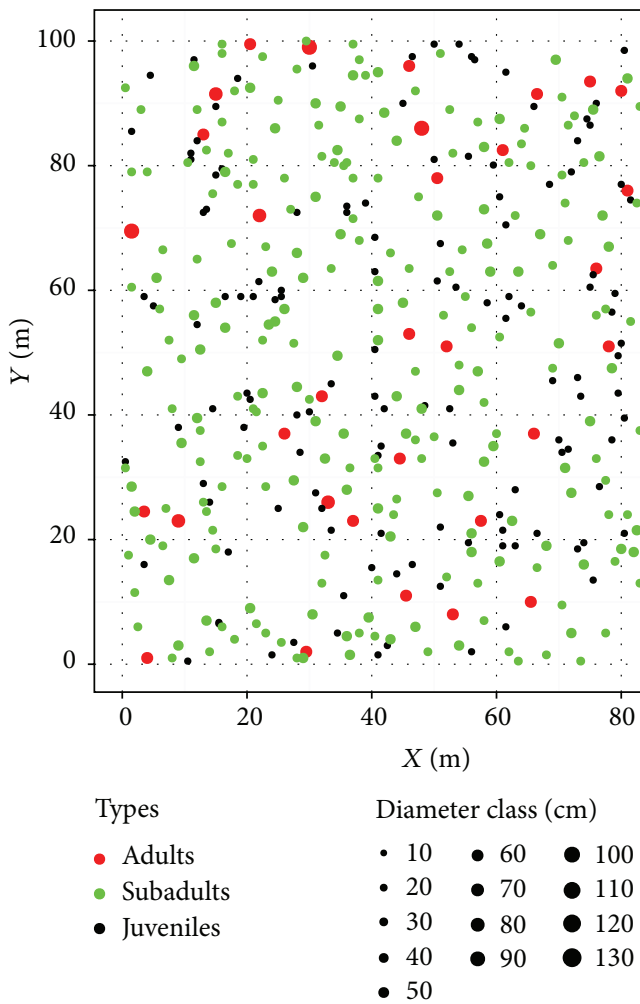

(c)

FIGURE 3: Distribution of all tree individuals in the three life stages: "juveniles," "subadults," and "adults." Symbol size is proportional to the $\mathrm{DBH}$ of the individuals with an actual size from 6.0 to $129.2 \mathrm{~cm}$. The unit of $(X, Y)$ axes is meter, where (a) is the undisturbed forest, (b) the lightly disturbed forest, and (c) the highly disturbed forest. 


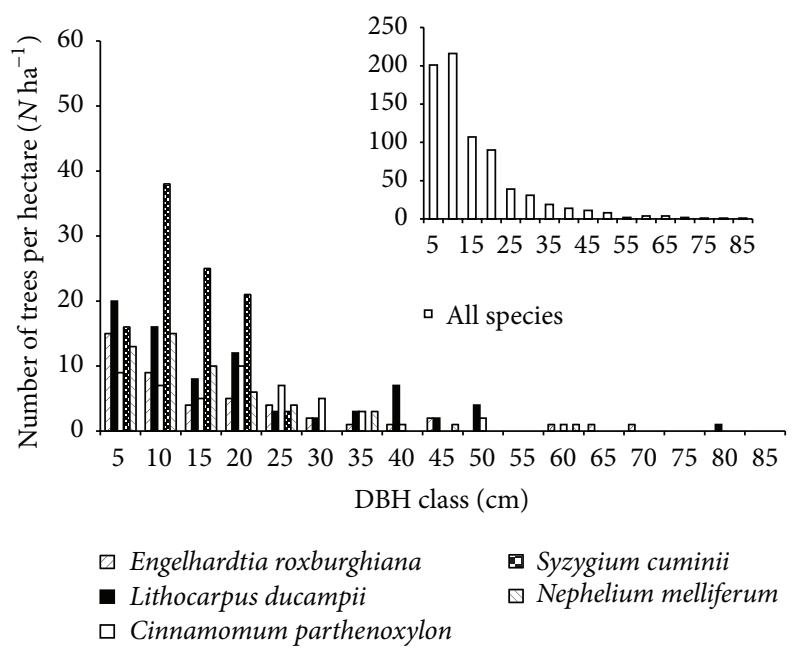

(a) Undisturbed forest

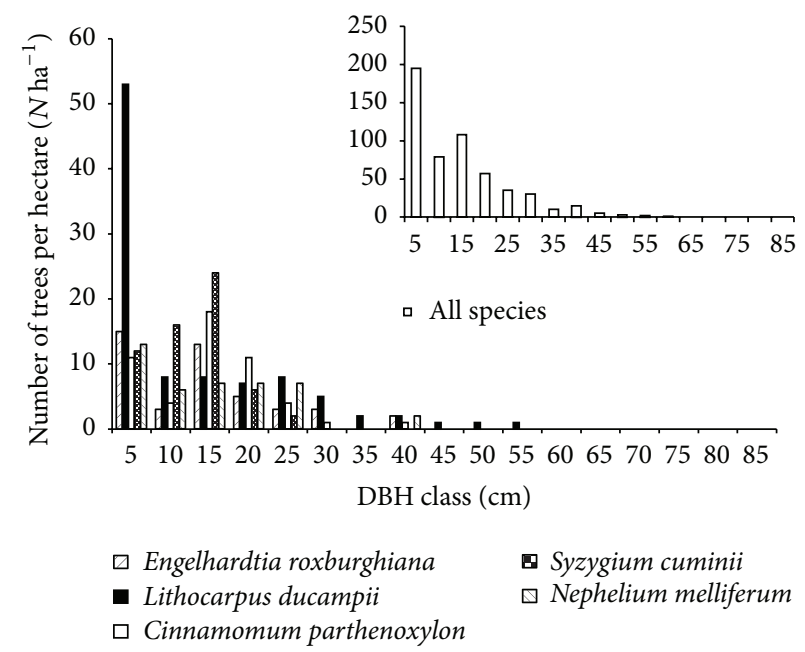

(b) Lightly disturbed forest

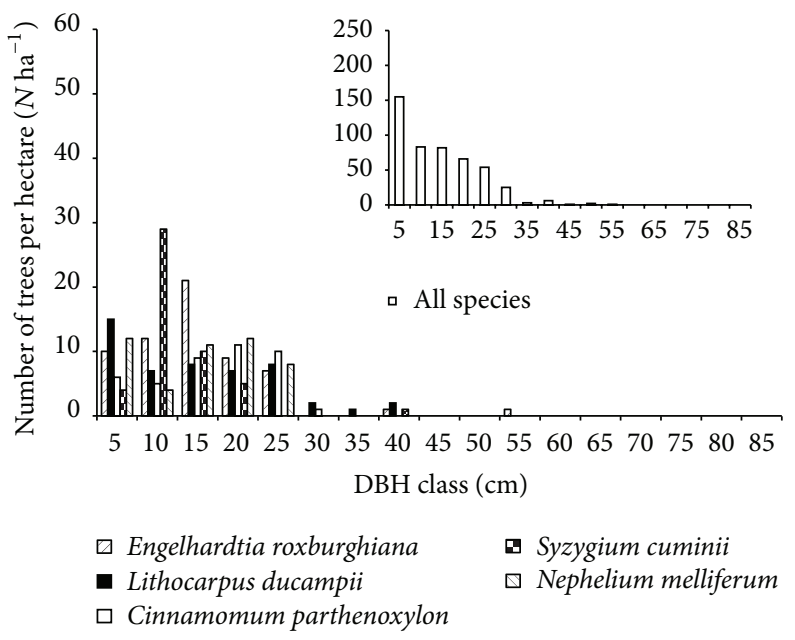

(c) Highly disturbed forest

FiguRE 4: Diameter distributions of all living trees and the five major tree species in each forest type in Xuan Nha Nature Reserve, Vietnam.

significant positive spatial association at scales of 5 and $31 \mathrm{~m}$ with a significant negative spatial association at 7, 9, and $30 \mathrm{~m}$ (Figure 8(l)).

The complementary analyses using the mark-correlation function are shown in Figure 9. Engelhardtia roxburghiana and Lithocarpus ducampii were spatially uncorrelated at all scales in the three forest types, but the former displayed a negative spatial interaction with Cinnamomum parthenoxylon at scales of $18-20 \mathrm{~m}$ in the HDF (Figure 9(a)); this interaction was strongly positive at 7-9, 21-24, and $36 \mathrm{~m}$ in the UDF (Figure 9(b)). A significant negative association was observed between Lithocarpus ducampii and Cinnamomum parthenoxylon at small scales of $3 \mathrm{~m}$ and greater than $32-33 \mathrm{~m}$ in the HDF (Figure 9(c)), whereas no spatial interaction was recorded in the UDF. In the HDF, however, two tendencies were obtained between Lithocarpus ducampii and Nephelium melliferum: a positive association at scales of 6 and $8-9 \mathrm{~m}$ and a significant repulsion at a scale greater than $30 \mathrm{~m}$ (Figure $9(\mathrm{~d})$ ). Cinnamomum parthenoxylon showed a negative spatial interaction with Syzygium cuminii at the range of 24$25 \mathrm{~m}$ in the UDF (Figure 9(e)), whereas in the HDF and LDF sites there was only a spatially independent interaction between them. A similar result was obtained for Syzygium cuminii and Nephelium melliferum in different scales; they showed a significant repulsion at spatial distances of 6, 10-12, and $15-16 \mathrm{~m}$ in the UDF (Figure 9(f)).

\section{Discussion}

4.1. Intraspecific Competition. Environmental heterogeneity and dispersal limitation, which usually influence the largescale spatial patterns of trees, are important processes that lead to an aggregation pattern [41, 42]. Our investigation revealed that there was change in the spatial distribution from aggregation to randomness (and even to regularity) for the five most abundant species; these displayed a significant degree of spatial aggregation at several small distances of 10,30 , and $40 \mathrm{~m}$ (Figure 4), suggesting the importance of 


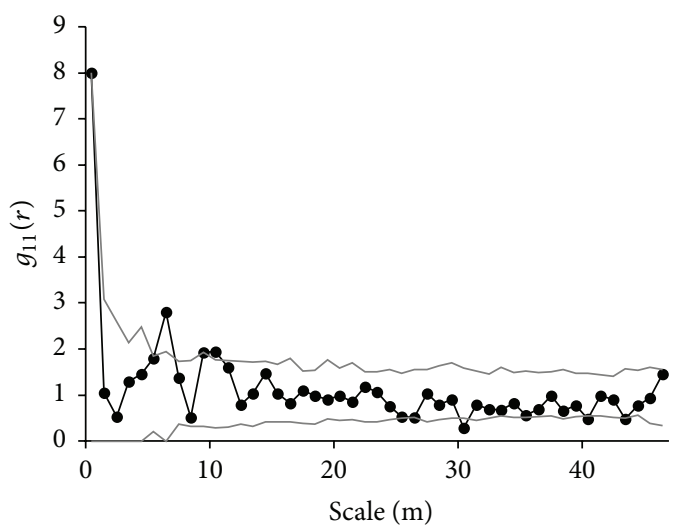

(a) E. roxburghiana (UDF)

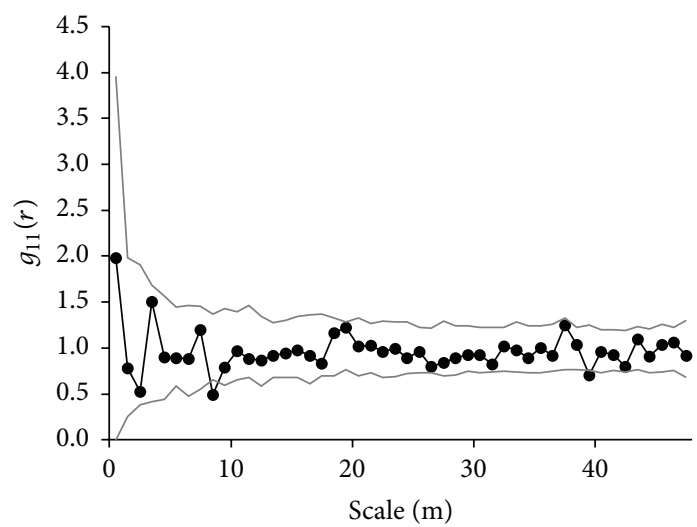

(c) L. ducampii (LDF)

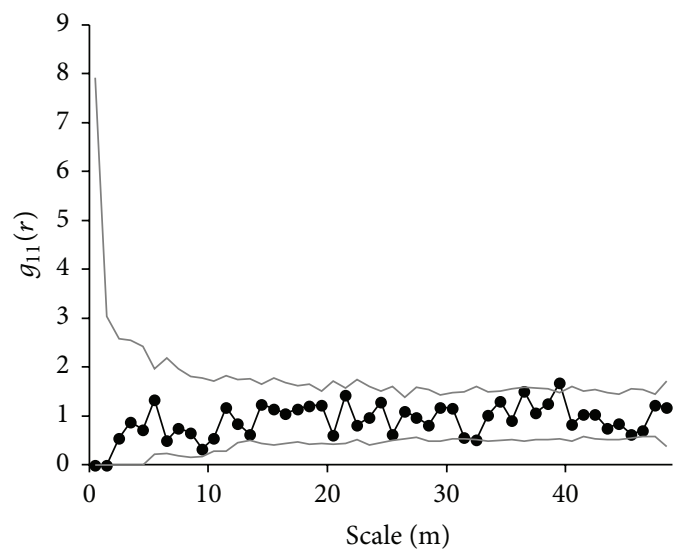

(e) S. cuminii (HDF)

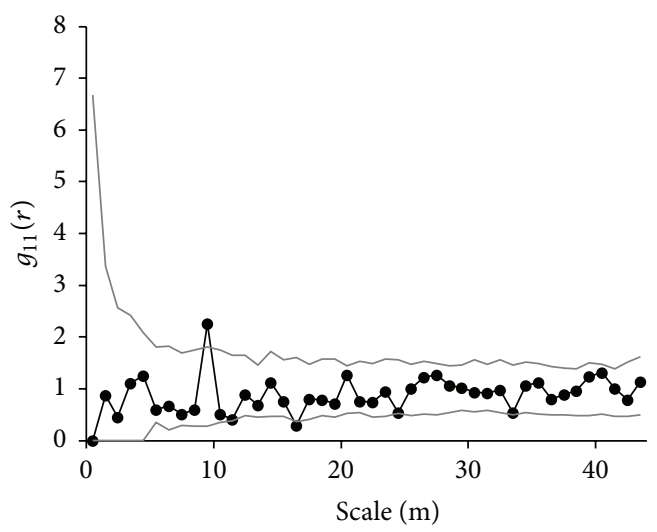

(b) L. ducampii (HDF)

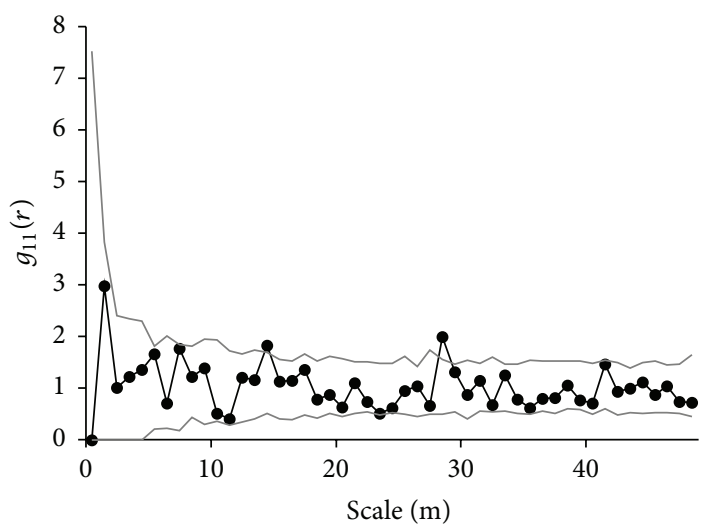

(d) C. parthenoxylon (UDF)

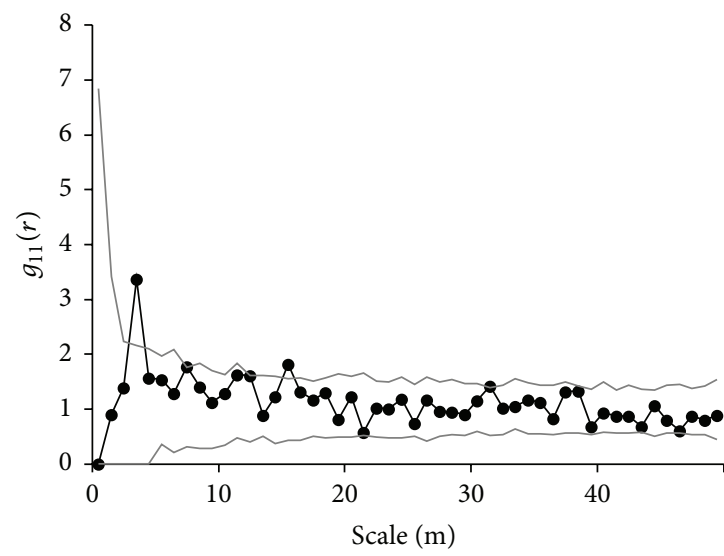

(f) N. melliferum (UDF)

FIGURE 5: Spatial patterns of the five most abundant tree species shown by the pair-correlation function $g(r)$ with the null model of CSR. Black lines are observed patterns and grey lines are approximate $95 \%$ confidence envelopes.

intraspecific competition in governing the spatial distribution and traits of tree populations in these forests. Of the five most abundant species, Engelhardtia roxburghiana and Syzygium cuminii had a widely distributed aggregation in this area. Lithocarpus ducampii was only found to have a regular distribution as succession progressed, providing further evidence of competition in the development of an evergreen forest structure. Hubbell [12] and Condit et al. [43] suggested that poor seed dispersal is related to greater clumping intensities of populations; however, our results showed that aggregations of abundant species were relatively loose [44]. At a given scale of observation, it has been found that the aggregation pattern occurs more frequently than random and regular patterns in natural tropical forests, where large trees organize themselves in a regular way [5]. However, this general rule did not apply to the Xuan Nha forests.

The question of whether trees compete in larger size classes $[5,45]$ is important for our general understanding of 


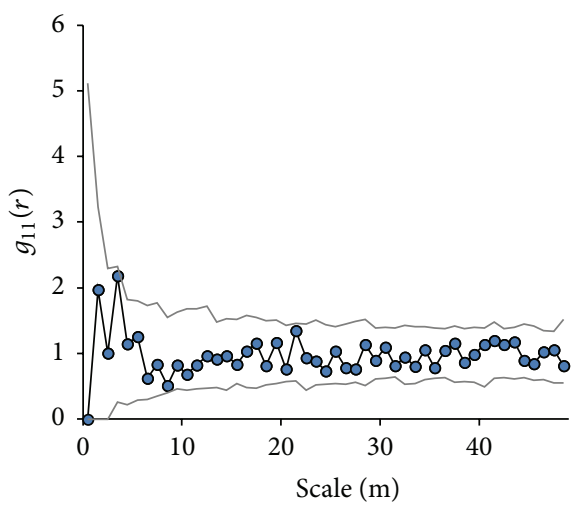

(a) E. roxburghiana (HDF)

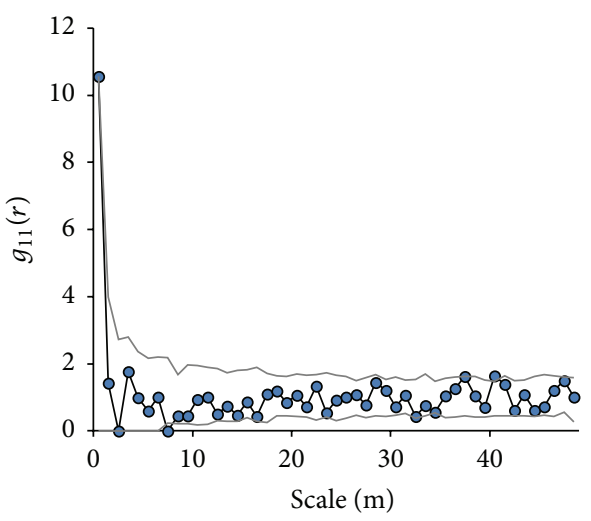

(c) C. parthenoxylon (HDF)

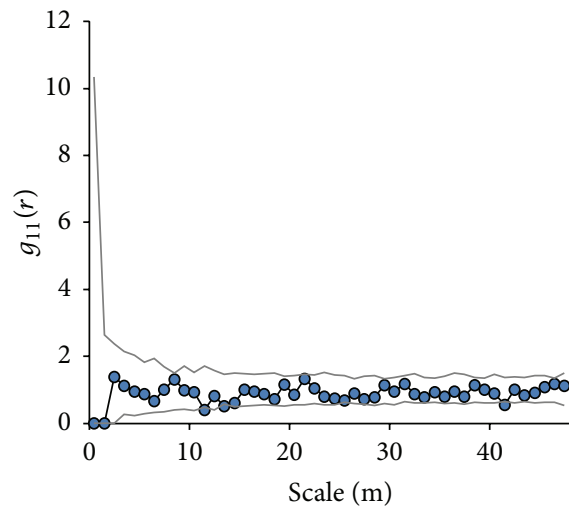

(e) S. cuminii (LDF)

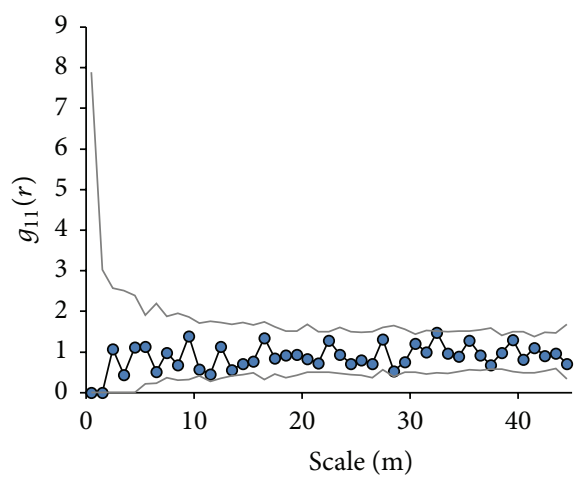

(g) N. Melliferum (HDF)

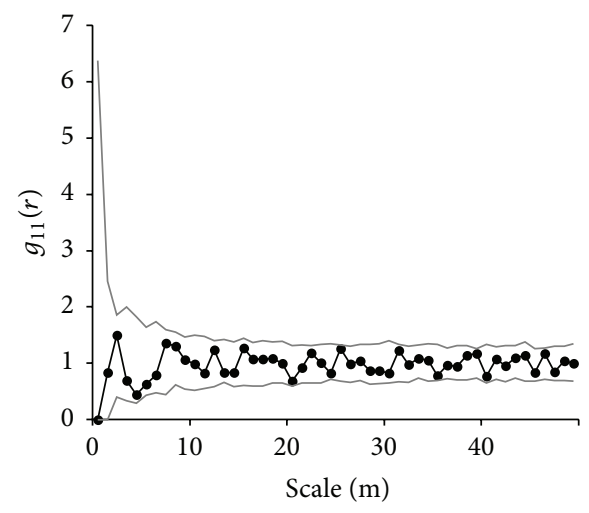

(b) L. Ducampii (UDF)

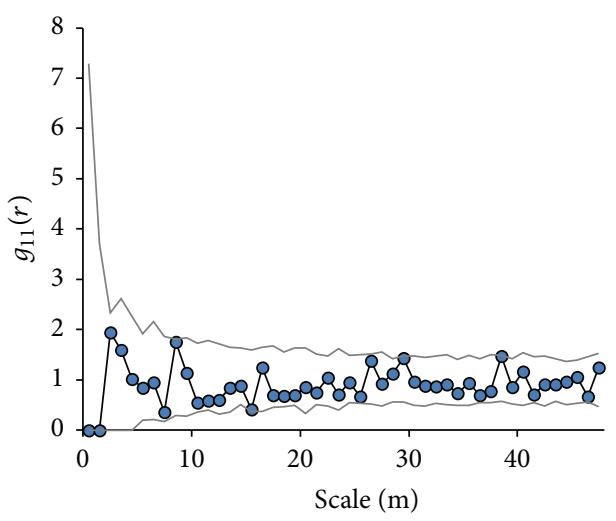

(d) C. parthenoxylon (LDF)

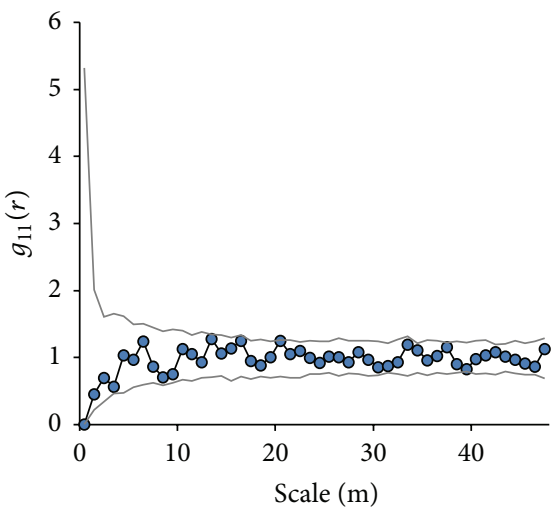

(f) S. cuminii (UDF)

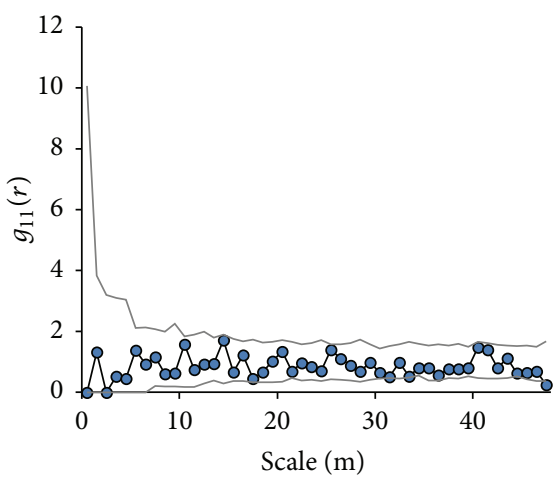

(h) N. Melliferum (LDF)

FIGURE 6: Spatial patterns of the five most abundant tree species shown by the pair-correlation function $g(r)$ with the null model of CSR. Black lines are observed patterns and grey lines are approximate $95 \%$ confidence envelopes. 


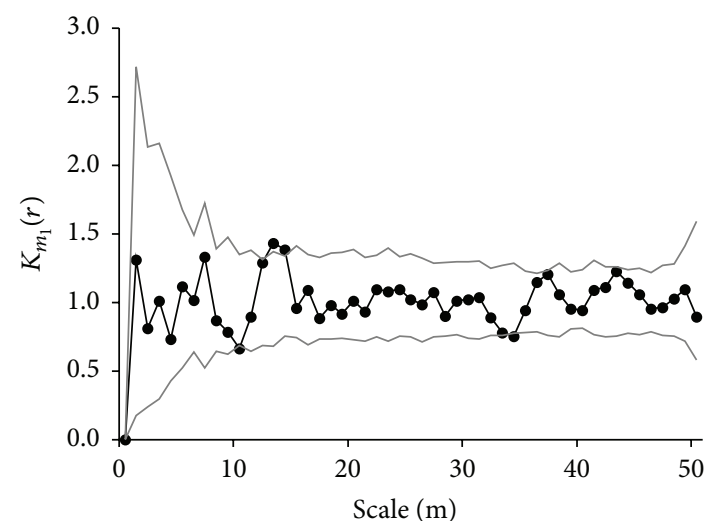

(a) E. roxburghiana (LDF)

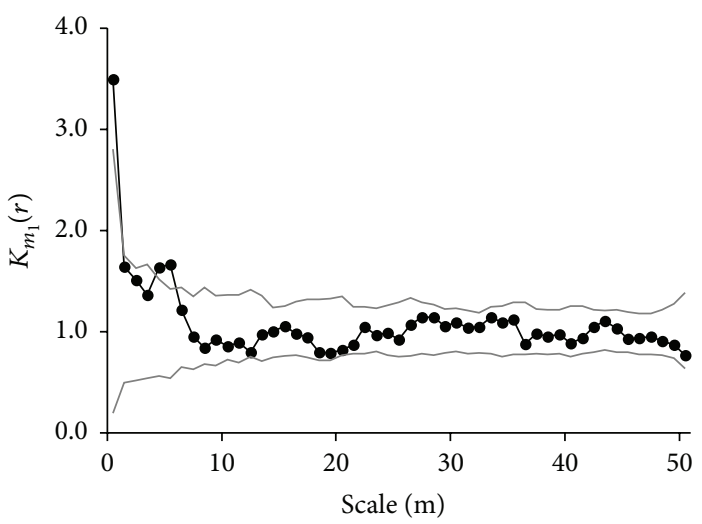

(c) L. ducampii (LDF)

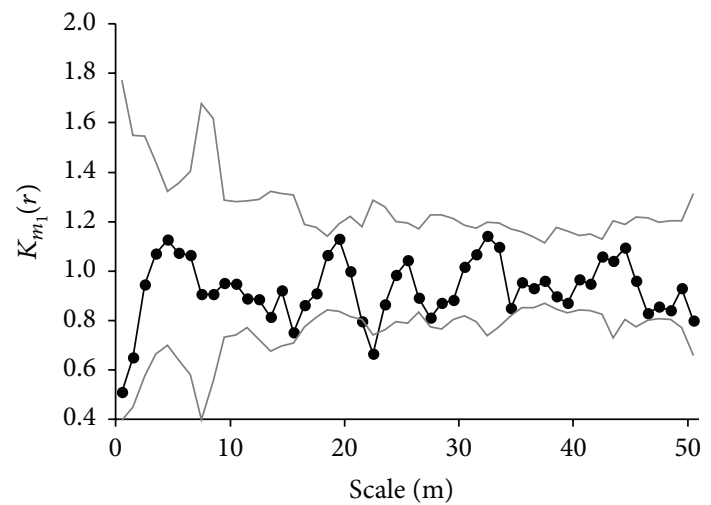

(e) C. parthenoxylon (HDF)

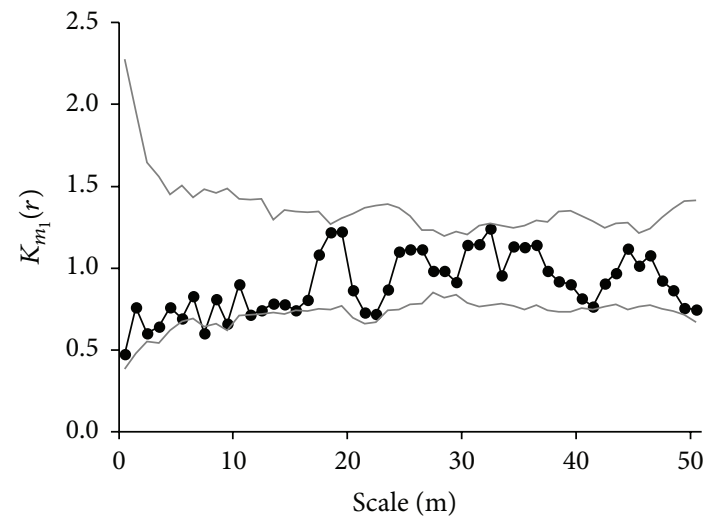

(g) C. parthenoxylon (UDF)

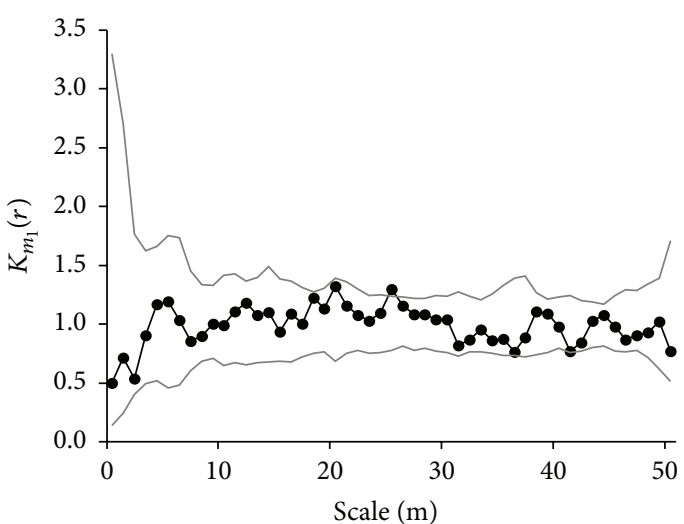

(b) L. ducampii (HDF)

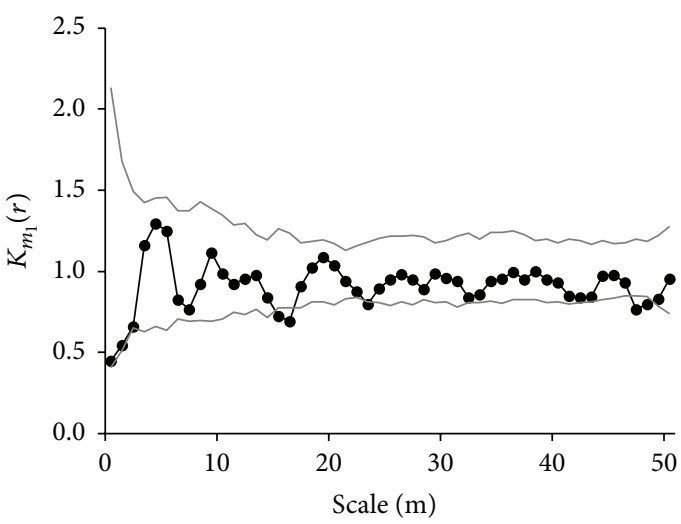

(d) L. ducampii (UDF)

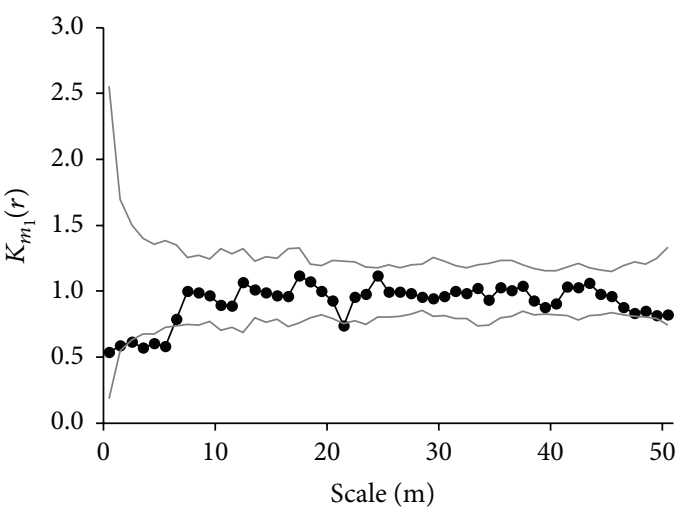

(f) C. parthenoxylon (LDF)

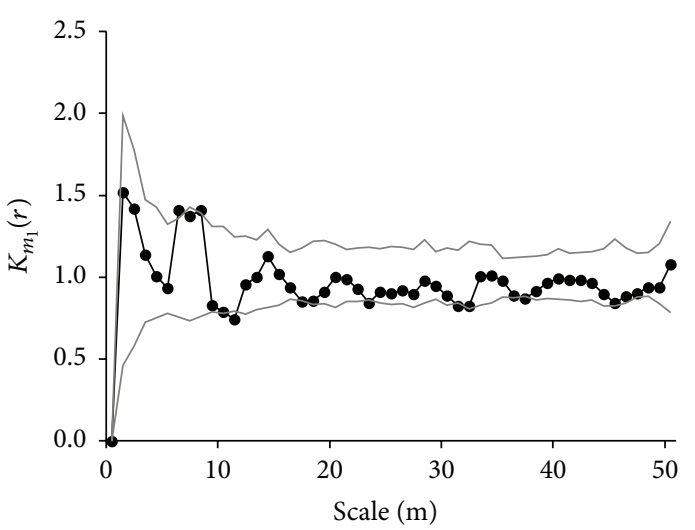

(h) S. cuminii (HDF)

FIgURE 7: Continued. 


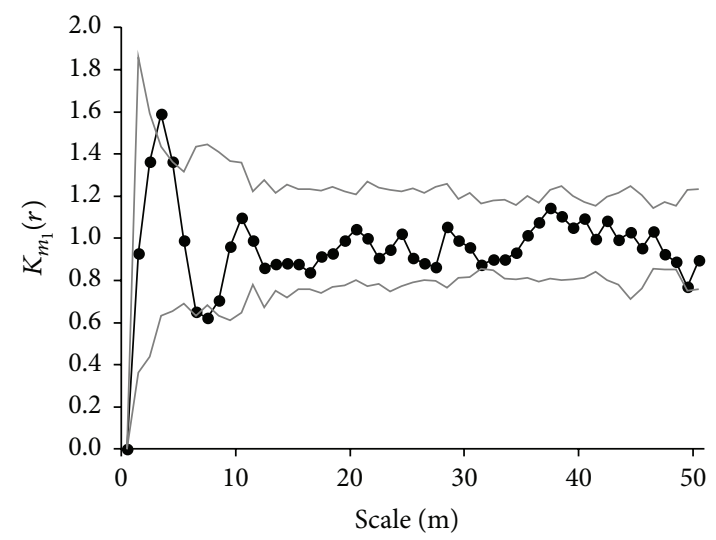

(i) N. melliferum (HDF)

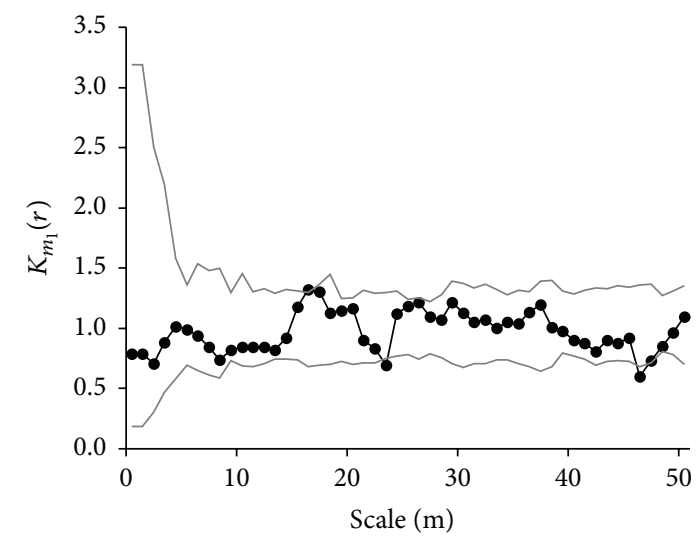

(j) N. melliferum (LDF)

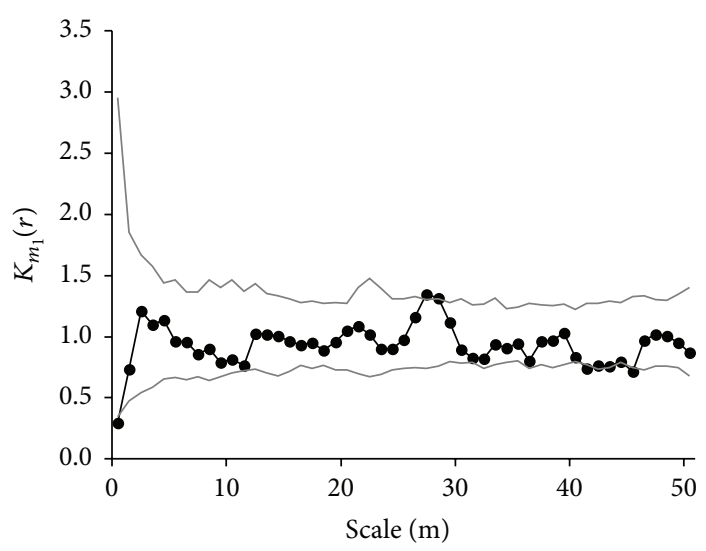

(k) N. melliferum (UDF)

FIGURE 7: Spatial patterns of the five most abundant tree species shown by mark-correlation function with the null model of uncorrelated marks. Black lines are observed patterns and grey lines are approximate $95 \%$ confidence envelopes.

tropical forest ecology. Three different patterns (regularity, randomness, and clumping with a tendency towards regularity) were found by Pélissier [46] among large adult trees in three different plots in tropical India. This was also recorded in our results, but these patterns tended toward randomness. We found evidence for competition among trees within the smaller size classes of the three forest types, but this competition was lower than expected given their relatively high densities; indeed, there was only slight regularity or aggregation at a radius of less than $10 \mathrm{~m}$. Clustered spatial distributions are often typical in naturally regenerated stands [47]. In very old forests at Wind River on the Pacific coast of the USA, North et al. [48] found that trees were clustered at all distances. Clustering also appeared to be present at shorter distances, although this was not seen as differing from a random spatial process [49].

4.2. Interspecific Competition. In this study, we conducted a comprehensive spatial pattern analysis to assess species associations among the five most abundant tree species across three different tropical forest types in Northern Vietnam. These species comprised $43.9 \%, 54.1 \%$, and $52.1 \%$ of all trees in the UDF, LDF, and HDF sites, respectively. Analogous analyses of data from tropical forests in Sinharaja (Sri Lanka) and Barro Colorado Island (Panama) also revealed significant small-scale associations [27]. However, we cannot exclude the possibility that these differences may owe as much to variation in other factors such as environmental heterogeneity, range of conditions, or species richness. Further comparisons across sites would help to assess the effects of these possibilities. Our analyses therefore indicate that there were some small differences between the spatial structures of the Changbaishan (CBS) and Xuan Nha forests; for example, we found that most species cooccurred in small neighborhoods less often than expected. Only $8 \%$ of all species pairs shared roughly the same plot areas in the CBS forests [50], whereas most Xuan Nha plot species pairs interacted both at small and large scales, or else had no association. Individuals of different species thus showed a clear tendency towards independence of one another at all distances.

The analyses of spatial association patterns among the five abundant species in the three different forest types present in Xuan Nha Nature Reserve revealed a balance between the attraction and repulsion interaction of spatial structures. The selective analysis of small-scale effects found surprising results, especially because more than one-third of all species pairs had independent association at all scales. We also found that the positive small-scale association pattern was caused by 


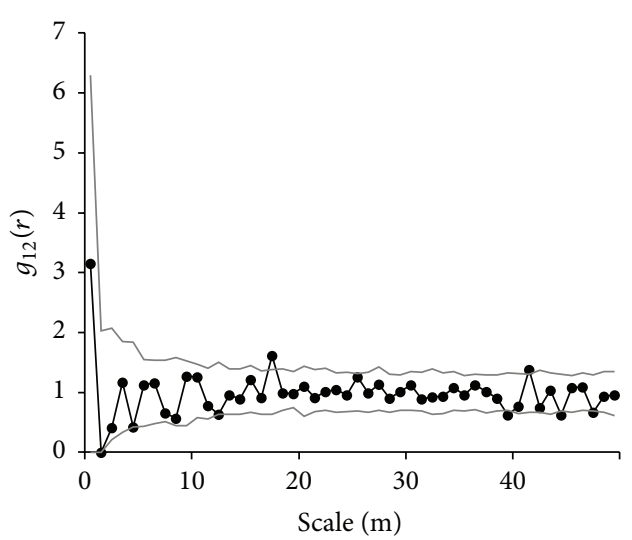

(a) E. roxburghiana and L. ducampii (HDF)

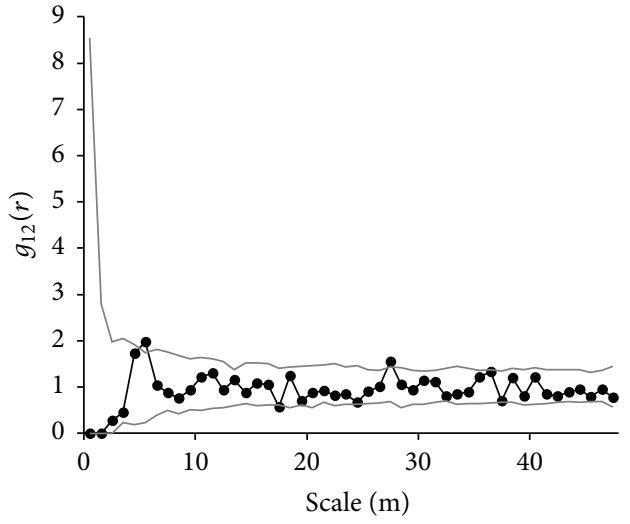

(c) E. roxburghiana and C. parthenoxylon (LDF)

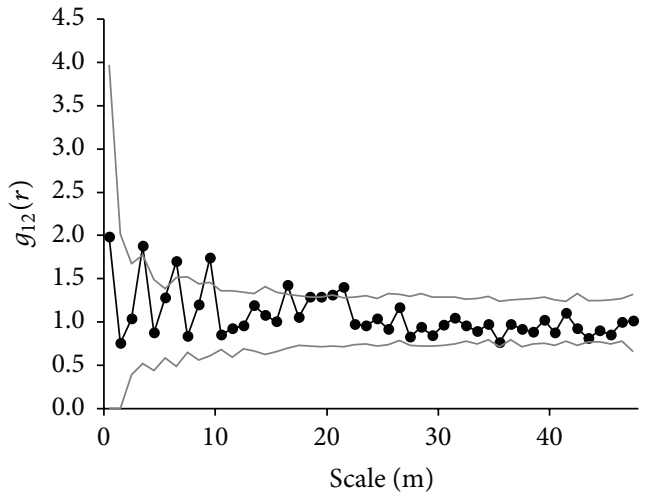

(e) E. roxburghiana and S. cuminii (UDF)

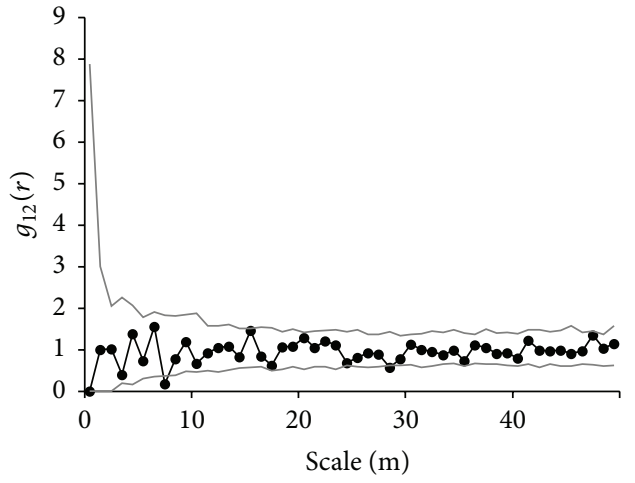

(g) E. roxburghiana and N. melliferum (UDF)

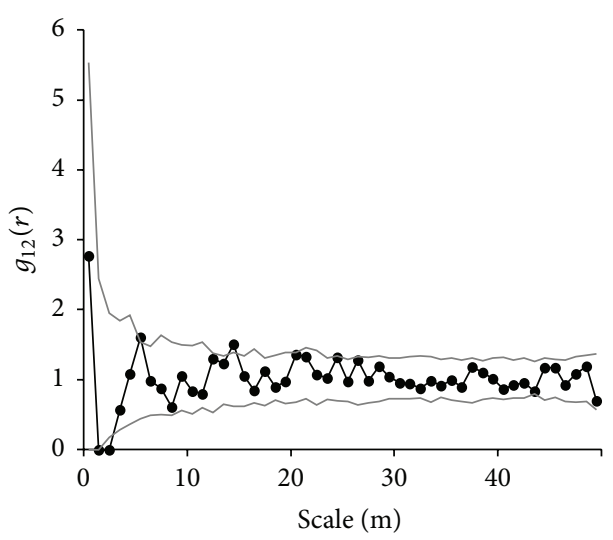

(b) E. roxburghiana and L. ducampii (UDF)

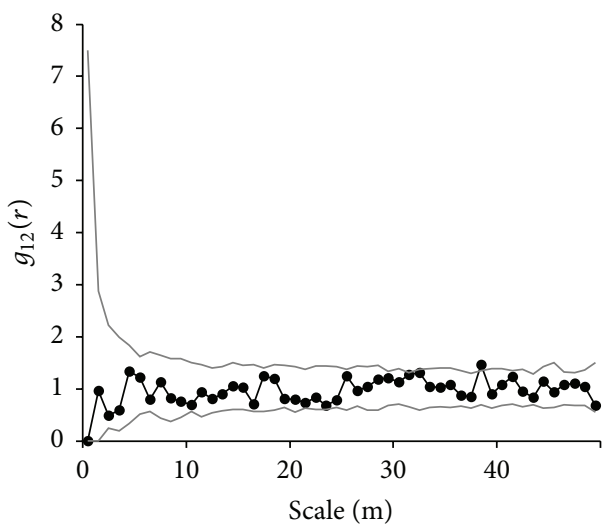

(d) E. roxburghiana and C. parthenoxylon (HDF)

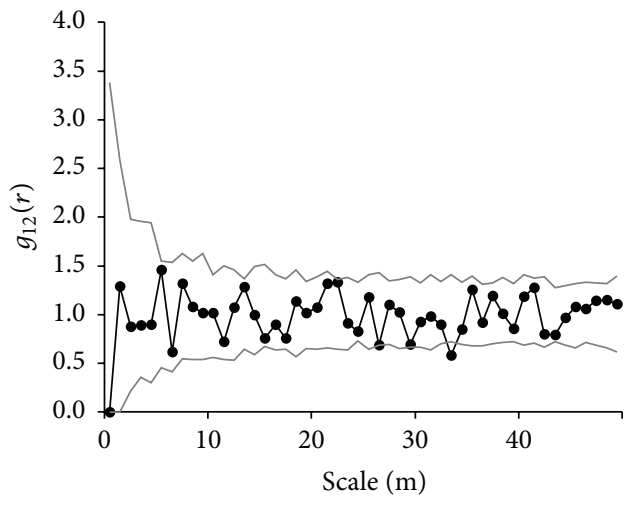

(f) E. roxburghiana and N. melliferum (HDF)

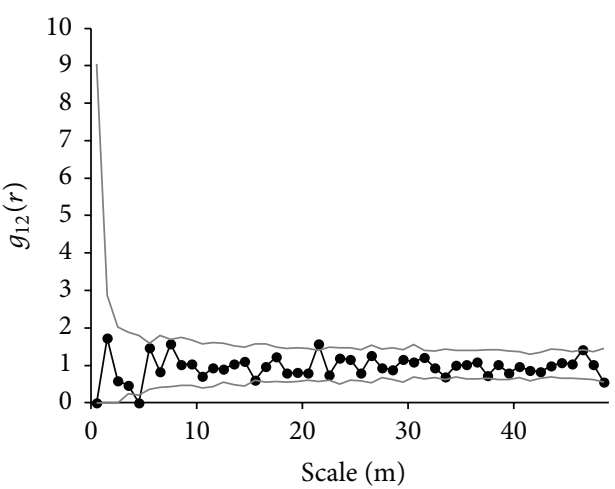

(h) L. ducampii and C. parthenoxylon (HDF)

Figure 8: Continued. 


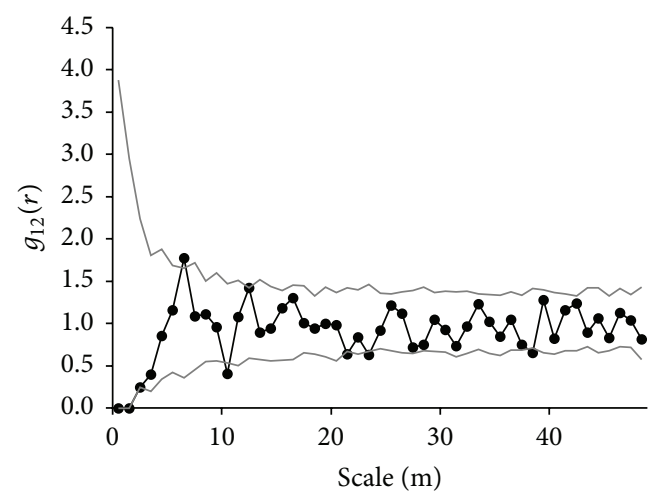

(i) L. ducampii and S. cuminii (HDF)

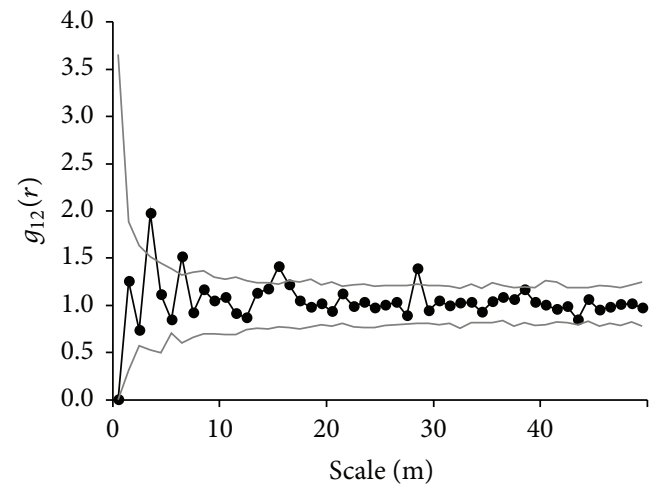

(k) L. ducampii and S. cuminii (UDF)

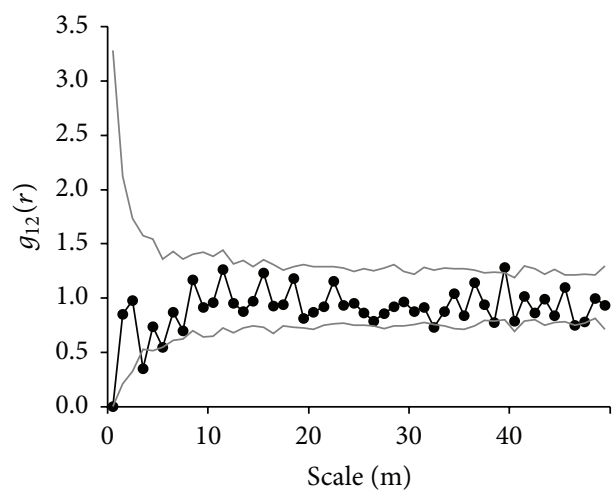

(j) L. ducampii and S. cuminii (LDF)

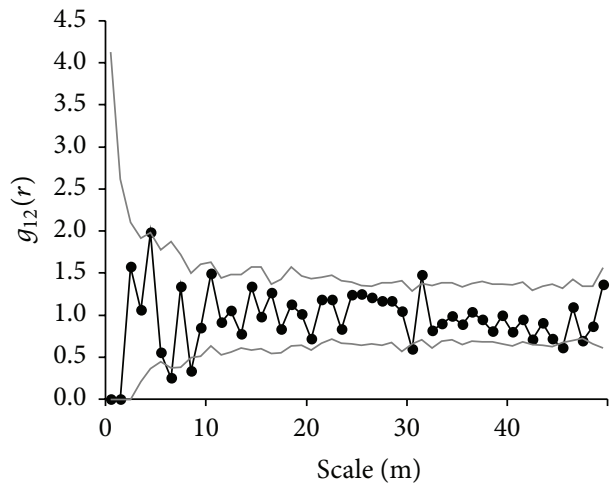

(1) L. ducampii and N. melliferum (HDF)

FIGURE 8: Spatial correlations among the five most abundant tree species are shown by the bivariate pair-correlation. The observed patterns (dark line) that lie beyond the confidence envelopes (grey lines) indicate significant departures from the null models of toroidal shift (spatial independence).

the aggregation of neither small individuals nor larger trees. Small-scale attraction rather than competition appeared to be a critical factor in shaping spatial distribution patterns; positive associations at small distances can thus be expected when species have similar requirements for establishment. Likewise, there are positive interspecific neighborhood effects on tree survival (facilitation), and/or species are dispersed across the same microhabitats [51].

\section{Conclusion}

Our analysis based on a systematic design may have been constrained by a lack of observation (pseudoreplication). We used a single one-ha permanent sample plot per forest type, and while this may reflect current conditions, it does not facilitate a detailed statistical analysis. Other, more efficient methods are recommended for a better understanding of tree species' distribution/density and disturbance regimes. Our results indicate that high intensity human disturbance adversely affected floristic composition, tree species density, and diversity among the three forest types. The basal areas recorded in the three forest types are quite low; indicating that these forests should be conserved and protected and all timber cutting and logging activities (legal or illegal) should be avoided until the forest recovers in terms of quantity and quality. Enrichment planting for species with low densities in the disturbed forests should be carried out; the promotion of natural regeneration by tending, weeding, and making bare soil in this area will also accelerate the recovery process.

The main goals of the present study were to detect the effects of disturbance degrees on the spatial patterns and distributions of tree species. Through spatial point-pattern analyses, our results clearly show the impacts of disturbance degrees on horizontal structure, and intra- and interspecific interactions. The univariate and bivariate data with pairand mark-correlation functions of intra- and interspecific interactions within the five most abundant tree species indicate that most species demonstrated clumping and regular distributions at small scales. A high proportion of negative interspecific small-scale association (inhibition) and positive association (attraction) were recorded in both the LDF and HDF sites but were rare in the UDF. Based on the present results, silvicultural implications such as the site selection of enrichment planting and the promotion of natural regeneration could be applied in lightly and highly disturbed forests. We suggest that some species characterized by a negative interspecific association, for example, Lithocarpus ducampii and Cinnamomum parthenoxylon, should not be planted in homogeneous environments. This competition and difference in habitat existed in the LDF and HDF sites, while other habitat associations or dispersal limitations existed in the UDF. The results obtained from this study could 


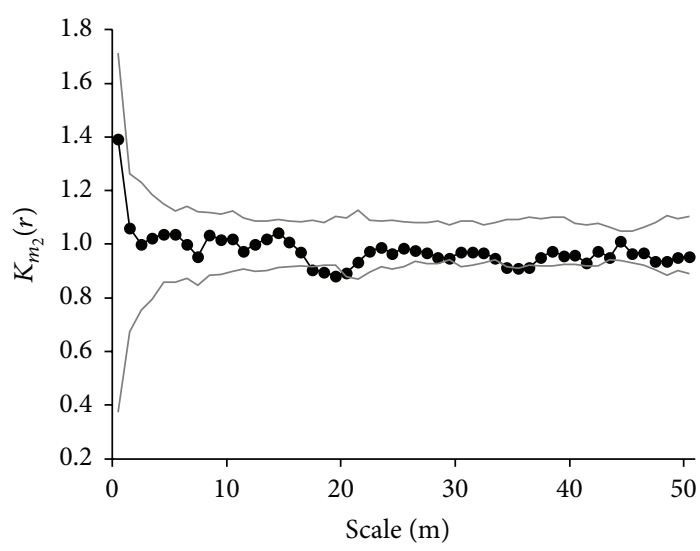

(a) E. roxburghiana and C. parthenoxylon (HDF)

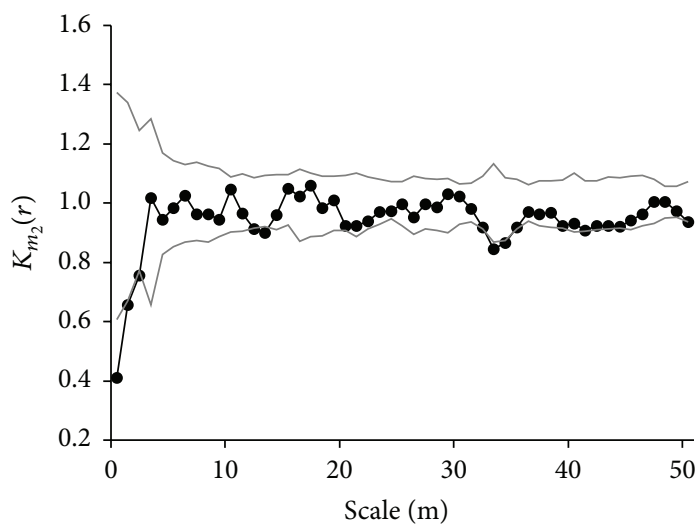

(c) L. ducampii and C. parthenoxylon (HDF)

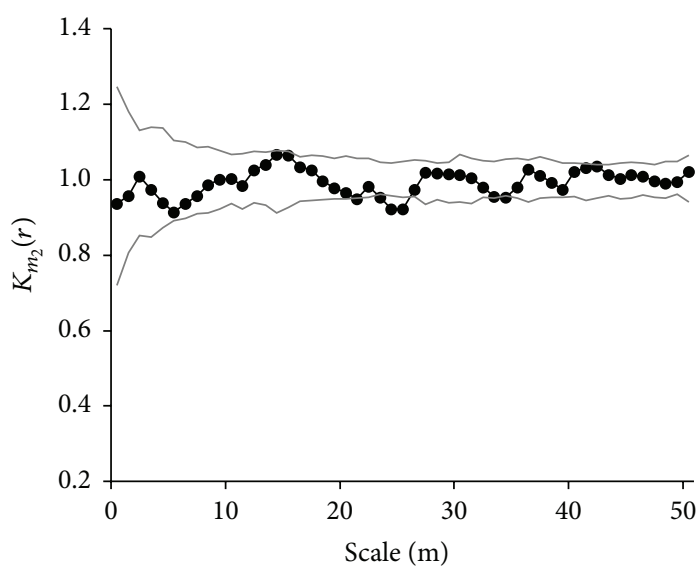

(e) C. parthenoxylon and S. cuminii (UDF)

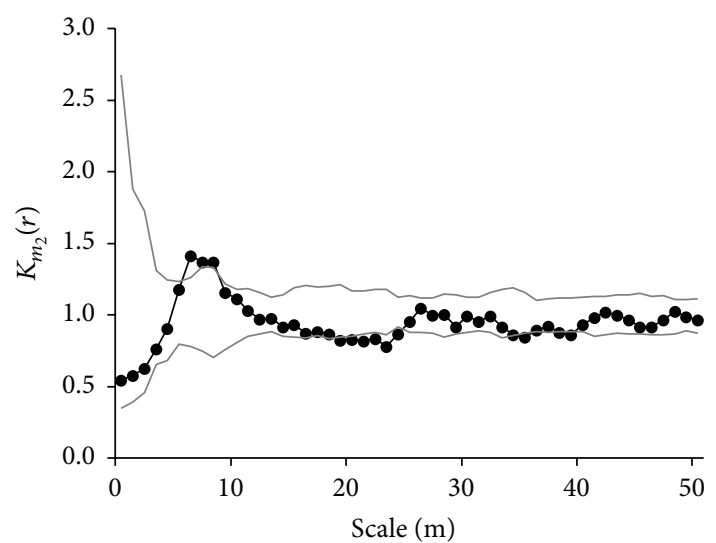

(b) E. roxburghiana and C. parthenoxylon (UDF)

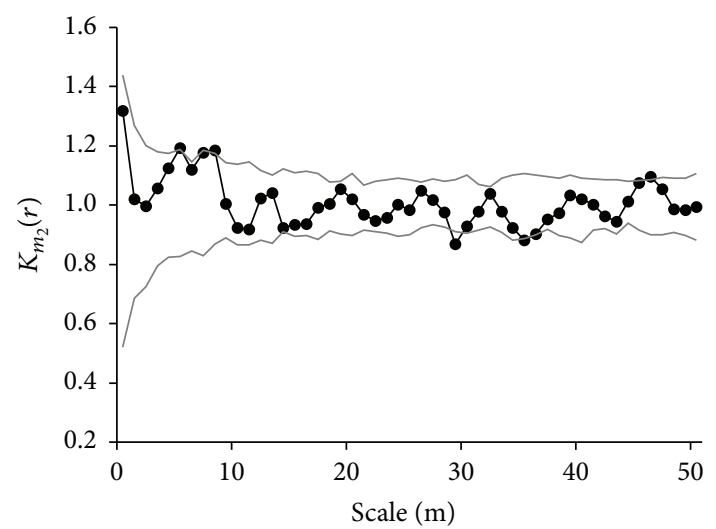

(d) L. Ducampii and N. melliferum (HDF)

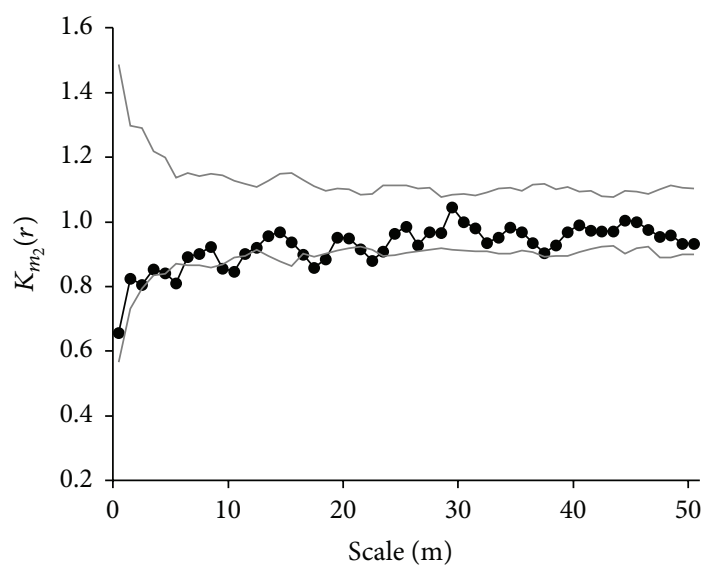

(f) S. Cuminii and N. Melliferum (UDF)

FIGURE 9: Spatial correlations among the five most abundant tree species are shown by the bivariate mark-correlation functions. The observed patterns (dark line) that lie beyond the confidence envelopes (grey lines) indicate significant departures from the null models of independent marks.

be improved if the series data regarding recruitment and mortality were available in order to explain the underlying dynamic processes.

\section{Conflict of Interests}

The authors declare that there is no conflict of interests regarding the publication of this paper.

\section{Acknowledgments}

The authors are grateful to the Forest Inventory and Planning Institute (FIPI) for providing data of the permanent sample plots. They wish to thank all the people who contributed to this work, especially Mr. Dung and Mr. Huong who identified tree species for them in the field. They profoundly thank the forest ranger, Mr. Phung Huu Thu, who worked with them 
under difficult conditions in the field. Thanks also go to Professor Dr. J. Saborowski who provided them with statistical advice at times of critical need. They thank Ms. Tina Marie Joaquim who corrected and checked grammatical errors in the paper. They acknowledge support by the German Research Foundation and the Open Access Publication Funds of the Göttingen University.

\section{References}

[1] G. Kunstler, C. H. Albert, B. Courbaud et al., "Effects of competition on tree radial-growth vary in importance but not in intensity along climatic gradients," Journal of Ecology, vol. 99, no. 1, pp. 300-312, 2011.

[2] M. Kariuki, M. Rolfe, R. G. B. Smith, J. K. Vanclay, and R. M. Kooyman, "Diameter growth performance varies with species functional-group and habitat characteristics in subtropical rainforests," Forest Ecology and Management, vol. 225, no. 1-3, pp. $1-14,2006$.

[3] J. Lancaster, "Using neutral landscapes to identify patterns of aggregation across resource points," Ecography, vol. 29, no. 3, pp. 385-395, 2006.

[4] L. Parrott and H. Lange, "Use of interactive forest growth simulation to characterise spatial stand structure," Forest Ecology and Management, vol. 194, no. 1-3, pp. 29-47, 2004.

[5] F. He, P. Legendre, and J. V. LaFrankie, "Distribution patterns of tree species in a Malaysian tropical rain forest," Journal of Vegetation Science, vol. 8, no. 1, pp. 105-114, 1997.

[6] J. A. Logan, P. White, B. J. Bentz, and J. A. Powell, "Model analysis of spatial patterns in mountain pine beetle outbreaks," Theoretical Population Biology, vol. 53, no. 3, pp. 236-255, 1998.

[7] C. Skarpe, "Spatial patterns and dynamics of woody vegetation in an arid savanna," Journal of Vegetation Science, vol. 2, no. 4, pp. 565-572, 1991.

[8] T. Wiegand and K. A. Moloney, "Rings, circles, and null-models for point pattern analysis in ecology," Oikos, vol. 104, no. 2, pp. 209-229, 2004.

[9] S. Barot, J. Gignoux, and J.-C. Menaut, "Demography of a savanna palm tree: predictions from comprehensive spatial pattern analyses," Ecology, vol. 80, no. 6, pp. 1987-2005, 1999.

[10] D. N. Hamill and S. J. Wright, "Testing the dispersion of juveniles relative to adults: a new analytic method," Ecology, vol. 67, no. 4, pp. 952-957, 1986.

[11] D. A. King, S. J. Wright, and J. H. Connell, "The contribution of interspecific variation in maximum tree height to tropical and temperate diversity," Journal of Tropical Ecology, vol. 22, no. 1, pp. 11-24, 2006.

[12] S. P. Hubbell, "Tree dispersion, abundance, and diversity in a tropical dry forest," Science, vol. 203, no. 4387, pp. 1299-1309, 1979.

[13] R. W. Sterner, C. A. Ribic, and G. E. Schatz, "Testing for life historical changes in spatial patterns of four tropical tree species," Journal of Ecology, vol. 74, no. 3, pp. 621-633, 1986.

[14] P. Haase, "Spatial pattern analysis in ecology based on Ripley's K-function: introduction and methods of edge correction," Journal of Vegetation Science, vol. 6, no. 4, pp. 575-582, 1995.

[15] S. Vacek and J. Lepš, "Spatial dynamics of forest decline: the role of neighbouring trees," Journal of Vegetation Science, vol. 7, no. 6, pp. 789-798, 1996.

[16] J. H. Hou, X. C. Mi, C. R. Liu, and K. P. Ma, "Spatial patterns and associations in a Quercus-Betula forest in northern China," Journal of Vegetation Science, vol. 15, no. 3, pp. 407-414, 2004.
[17] T. T. Veblen, D. H. Ashton, and F. M. Schlegel, “Tree regeneration strategies in a lowland Nothofagus-dominated forest in south-central Chile," Journal of Biogeography, vol. 6, no. 4, pp. 329-340, 1979 .

[18] J. F. Franklin, T. A. Spies, R. V. Pelt et al., "Disturbances and structural development of natural forest ecosystems with silvicultural implications, using Douglas-fir forests as an example," Forest Ecology and Management, vol. 155, no. 1-3, pp. 399-423, 2002.

[19] P. J. Diggle, Statistical Analysis of Spatial Point Patterns, Academic Press, London, UK, 1983.

[20] P. J. Clark and F. C. Evans, "Distance to nearest neighbor as a measure of spatial relationships in populations," Ecology, vol. 35, no. 4, pp. 445-453, 1954.

[21] P. Greig-smith, "The use of random and contiguous quadrats in the study of the structure of plant communities," Annals of Botany, vol. 16, no. 2, pp. 293-316, 1952.

[22] E. C. Pielou, "The use of point-to-plant distances in the study of the pattern of plant populations," Journal of Ecology, vol. 47, no. 3, pp. 607-613, 1959.

[23] B. D. Ripley, "Tests of 'randomness' for spatial point patterns," Journal of the Royal Statistical Society Series B: Methodological, vol. 41, no. 3, pp. 368-374, 1979.

[24] C. Hui, L. C. Foxcroft, D. M. Richardson, and S. MacFadyen, "Defining optimal sampling effort for large-scale monitoring of invasive alien plants: a Bayesian method for estimating abundance and distribution," Journal of Applied Ecology, vol. 48, no. 3, pp. 768-776, 2011.

[25] A. Pommerening, "Approaches to quantifying forest structures," Forestry, vol. 75, no. 3, pp. 305-324, 2002.

[26] D. Stoyan and H. Stoyan, Fractals, Random Shapes, and Point Fields: Methods of Geometrical Statistics, Wiley, Chichester, UK, 1994.

[27] T. Wiegand, S. Gunatilleke, and N. Gunatilleke, "Species associations in a heterogeneous Sri Lankan dipterocarp forest," The American Naturalist, vol. 170, no. 4, pp. 77-95, 2007.

[28] S. P. Hubbell, "Neutral theory and the evolution of ecological equivalence," Ecology, vol. 87, no. 6, pp. 1387-1398, 2006.

[29] S. Getzin and K. Wiegand, "Asymmetric tree growth at the stand level: random crown patterns and the response to slope," Forest Ecology and Management, vol. 242, no. 2-3, pp. 165-174, 2007.

[30] J. Illian, A. Penttinen, H. Stoyan, and D. Stoyan, Statistical Analysis and Modelling of Spatial Point Patterns, John Wiley \& Sons, 2008.

[31] P. Greig-Smith, "Pattern in vegetation," The Journal of Ecology, vol. 67, no. 3, pp. 755-779, 1979.

[32] J. Leps, "Can underlying mechanisms be deduced from observed patterns," in Spatial Processes in Plant Communities, F. Krahulec, A. D. Q. Agnew, and J. H. Willems, Eds., pp. 1-11, SPB Academic Publishing, The Hague, The Netherlands, 1990.

[33] A. S. Watt, "Pattern and process in the plant community," The Journal of Ecology, vol. 35, no. 1/2, pp. 1-22, 1947.

[34] A. W. Tordoff, B. Q. Tran, T. D. Nguyen, and H. M. Le, Sourcebook of Existing and Proposed Protected Areas in Vietnam, Birdlife International in Indochina and Ministry of Agriculture and Rural Development, Hanoi, Vietnam, 2004.

[35] Plan of conservation andsustainable development Xuan Nha Nature Reserve until 2020, Son La Protection of Department, 2013. 
[36] N. H. Hai, K. Wiegand, and S. Getzin, "Spatial distributions of tropical tree species in northern Vietnam under environmentally variable site conditions," Journal of Forestry Research, vol. 25, no. 2, pp. 257-268, 2014.

[37] B. Adrian and T. Rolf, "Spatstat: an R package for analyzing spatial point patterns," Journal of Statistical Software, vol. 12, no. 6, pp. 1-42, 2005.

[38] M. J. Lawes, M. E. Griffiths, J. J. Midgley, S. Boudreau, H. A. C. Eeley, and C. A. Chapman, "Tree spacing and area of competitive influence do not scale with tree size in an African rain forest," Journal of Vegetation Science, vol. 19, no. 5, pp. 729-738, 2008.

[39] S. Getzin, T. Wiegand, K. Wiegand, and F. He, "Heterogeneity influences spatial patterns and demographics in forest stands," Journal of Ecology, vol. 96, no. 4, pp. 807-820, 2008.

[40] F. Goreaud and R. Pélissier, "Avoiding misinterpretation of biotic interactions with the intertype $\mathrm{K} 12$-function: population independence vs. random labelling hypotheses," Journal of Vegetation Science, vol. 14, no. 5, pp. 681-692, 2003.

[41] S. Getzin, C. Dean, F. He, J. A. Trofymow, K. Wiegand, and T. Wiegand, "Spatial patterns and competition of tree species in a Douglas-fir chronosequence on Vancouver Island," Ecography, vol. 29, no. 5, pp. 671-682, 2006.

[42] G. Shen, M. Yu, X.-S. Hu et al., "Species-area relationships explained by the joint effects of dispersal limitation and habitat heterogeneity," Ecology, vol. 90, no. 11, pp. 3033-3041, 2009.

[43] R. Condit, P. S. Ashton, P. Baker et al., "Spatial patterns in the distribution of tropical tree species," Science, vol. 288, no. 5470, pp. 1414-1418, 2000.

[44] Z. Luo, B. Ding, X. Mi, J. Yu, and Y. Wu, "Distribution patterns of tree species in an evergreen broadleaved forest in eastern China," Frontiers of Biology in China, vol. 4, no. 4, pp. 531-538, 2009.

[45] H. A. Peters, "Neighbour-regulated mortality: the influence of positive and negative density dependence on tree populations in species-rich tropical forests," Ecology Letters, vol. 6, no. 8, pp. 757-765, 2003.

[46] R. Pélissier, "Tree spatial patterns in three contrasting plots of a southern Indian tropical moist evergreen forest," Journal of Tropical Ecology, vol. 14, no. 1, pp. 1-16, 1998.

[47] A. Van Laar and A. Akça, Forest Mensuration, Managing Forest Ecosystems, Springer Science \& Business Media, 1997.

[48] M. North, J. Chen, B. Oakley et al., "Forest stand structure and pattern of old-growth western hemlock/Douglas-fir and mixedconifer forests," Forest Science, vol. 50, no. 3, pp. 299-311, 2004.

[49] R. P. Duncan and G. H. Stewart, "The temporal and spatial analysis of tree age distributions," Canadian Journal of Forest Research, vol. 21, no. 12, pp. 1703-1710, 1991.

[50] X. Wang, T. Wiegand, Z. Hao, B. Li, J. Ye, and F. Lin, "Species associations in an old-growth temperate forest in north-eastern China," Journal of Ecology, vol. 98, no. 3, pp. 674-686, 2010.

[51] I. Martínez, T. Wiegand, F. González-Taboada, and J. R. Obeso, "Spatial associations among tree species in a temperate forest community in North-western Spain," Forest Ecology and Management, vol. 260, no. 4, pp. 456-465, 2010. 

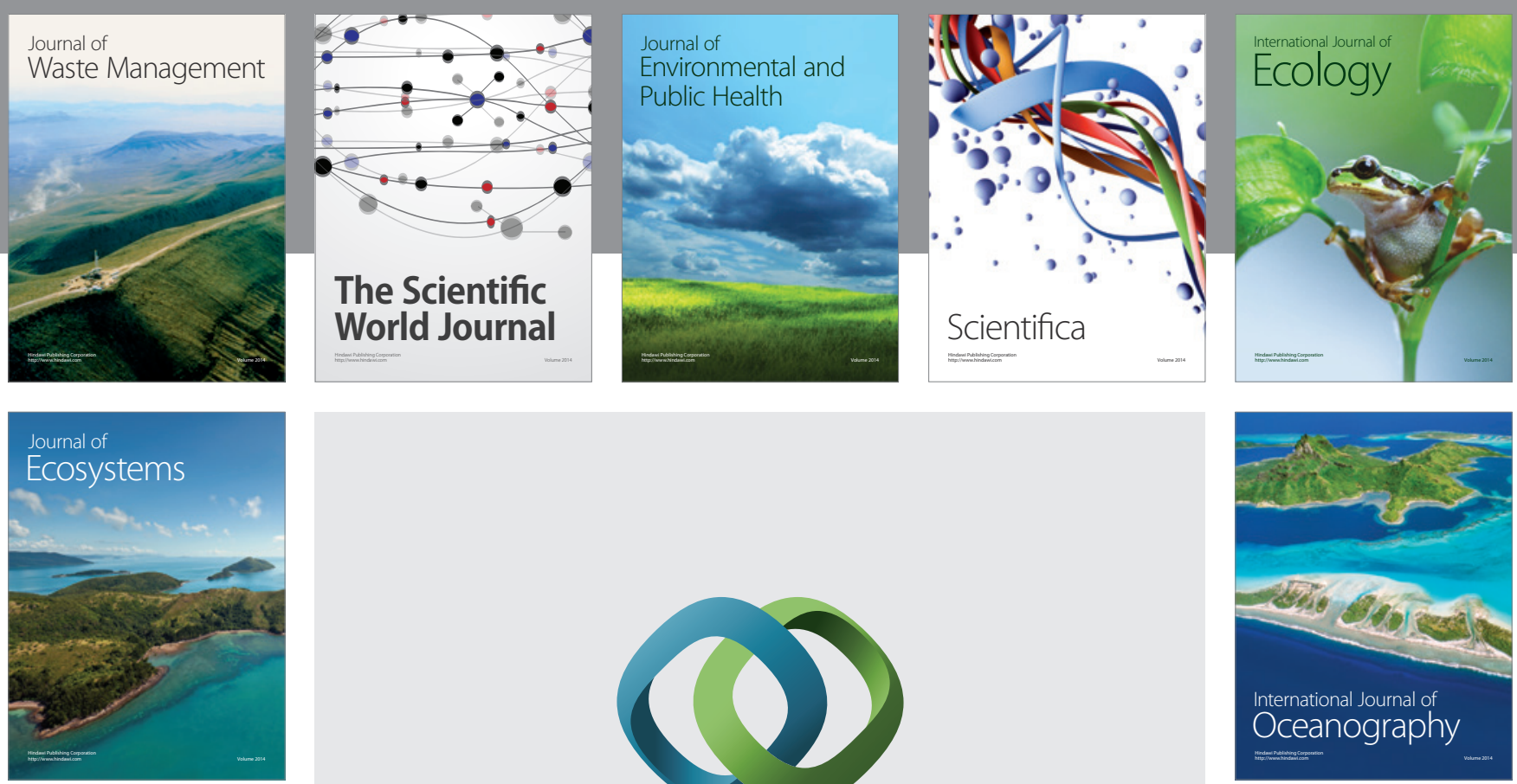

The Scientific World Journal
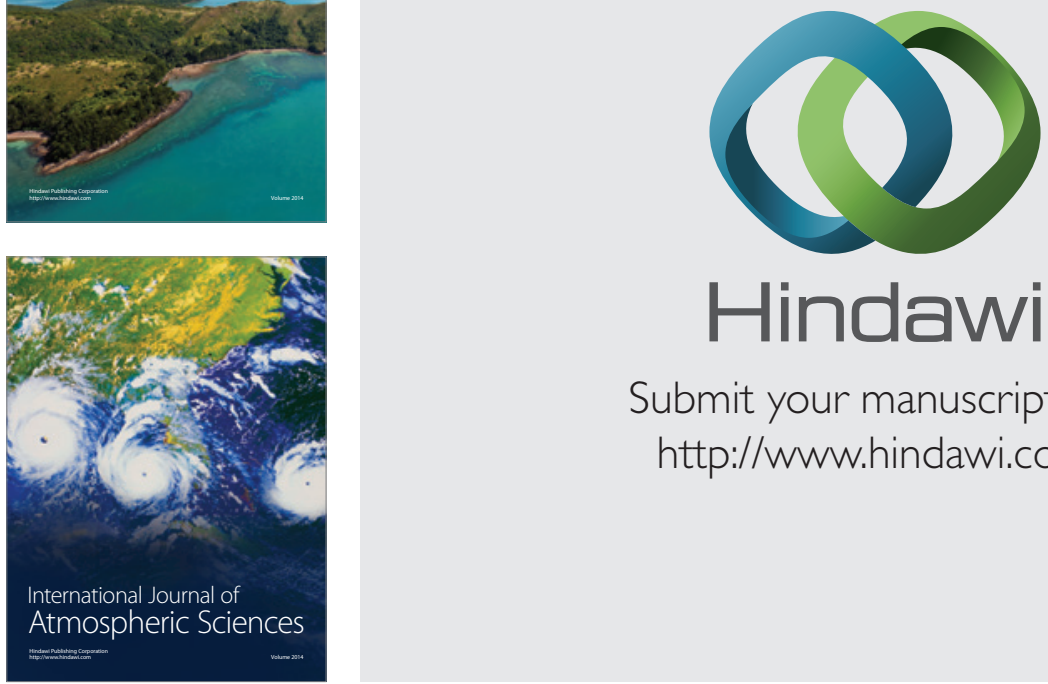

\section{Hindawi}

Submit your manuscripts at

http://www.hindawi.com
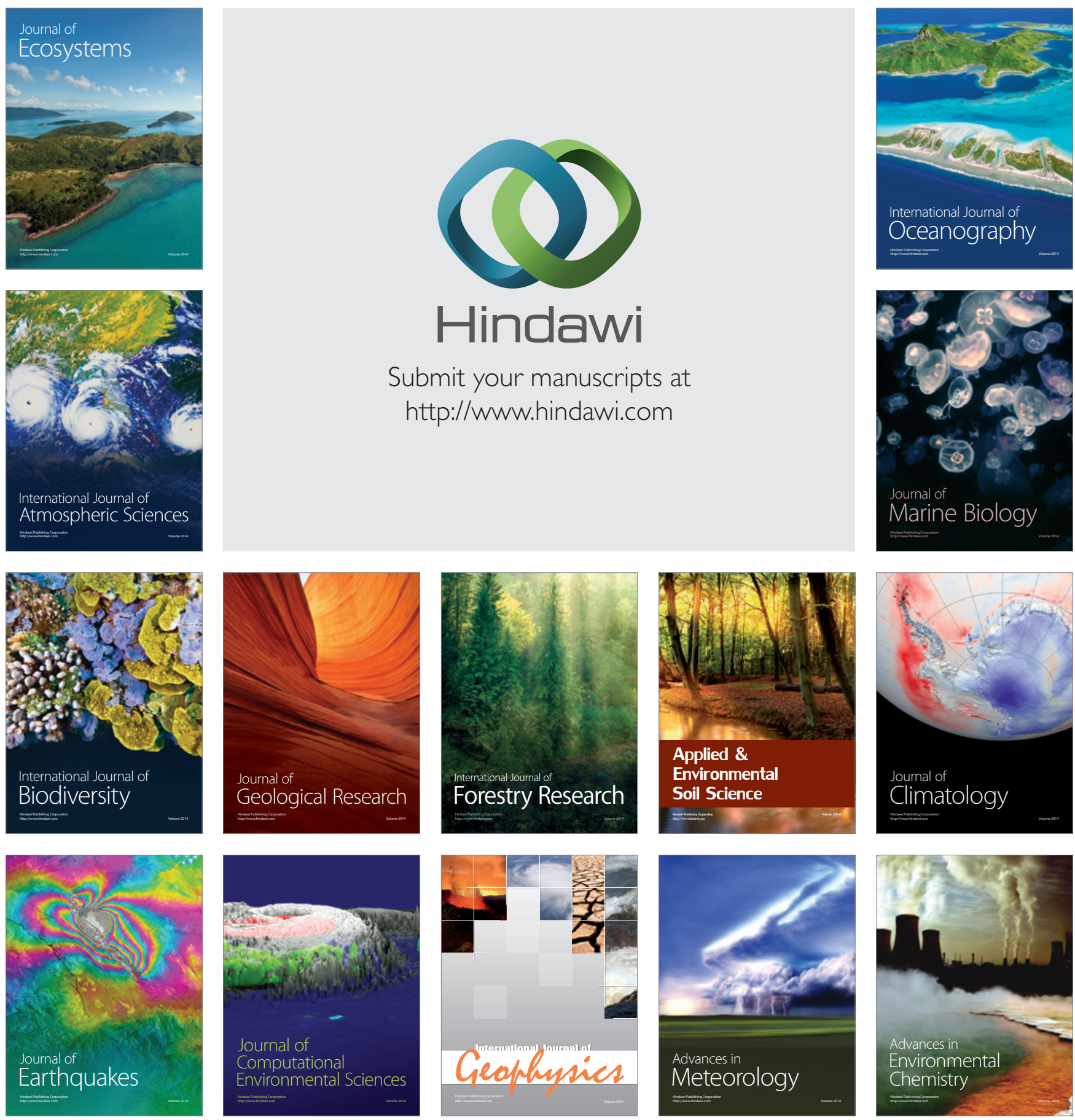